\title{
Microscopic characterization of carbonaceous aerosol particle aging in the outflow from Mexico City
}

\author{
R. C. Moffet ${ }^{1}$, T. R. Henn ${ }^{1,2}$, A. V. Tivanski ${ }^{1, *}$, R. J. Hopkins ${ }^{1}$, Y. Desyaterik ${ }^{3}{ }^{* *}$, A. L. D. Kilcoyne ${ }^{1}$, T. Tyliszczak ${ }^{1}$, \\ J. Fast ${ }^{4}$, J. Barnard ${ }^{4}$, V. Shutthanandan ${ }^{3}$, S. S. Cliff ${ }^{5}$, K. D. Perry ${ }^{6}$, A. Laskin ${ }^{3}$, and M. K. Gilles ${ }^{1}$ \\ ${ }^{1}$ Chemical Sciences Division, Lawrence Berkeley National Laboratory, Berkeley, California, 94720-8226, USA \\ ${ }^{2}$ Department of Physics, University of Würzburg, Am Hu-bland, 97074 Würzburg, Germany \\ ${ }^{3}$ W. R. Wiley Environmental Molecular Sciences Laboratory, Pacific Northwest National Laboratory, Richland, Washington, \\ 99352, USA \\ ${ }^{4}$ Atmospheric Science and Global Change Division, Pacific Northwest National Laboratory, Richland, Washington, \\ 99352, USA \\ ${ }^{5}$ Department of Applied Sciences, University of California, Davis, California, USA \\ ${ }^{6}$ Department of Meteorology, University of Utah, Salt Lake City, Utah, USA \\ * now at: Department of Chemistry, University of Iowa, Iowa City, Iowa 52242, USA \\ ** now at: Department of Atmospheric Science, Colorado State University, Fort Collins, Colorado, 80523-1371, USA
}

Received: 29 July 2009 - Published in Atmos. Chem. Phys. Discuss.: 12 August 2009

Revised: 3 December 2009 - Accepted: 5 January 2010 - Published: 1 February 2010

\begin{abstract}
This study was part of the Megacities Initiative: Local and Global Research Observations (MILAGRO) field campaign conducted in Mexico City metropolitan area during spring 2006. The physical and chemical transformations of particles aged in the outflow from Mexico City were investigated for the transport event of 22 March 2006. A detailed chemical analysis of individual particles was performed using a combination of complementary microscopy and micro-spectroscopy techniques. The applied techniques included scanning transmission X-ray microscopy (STXM) coupled with near edge X-ray absorption fine structure spectroscopy (NEXAFS) and computer controlled scanning electron microscopy with an energy dispersive $\mathrm{X}$-ray analyzer (CCSEM/EDX). As the aerosol plume evolves from the city center, the organic mass per particle increases and the fraction of carbon-carbon double bonds (associated with elemental carbon) decreases. Organic functional groups enhanced with particle age include: carboxylic acids, alkyl groups, and oxygen bonded alkyl groups. At the city center (T0) the most prevalent aerosol type contained inorganic species (composed of sulfur, nitrogen, oxygen, and potassium) coated with organic material. At the T1 and T2 sites, located northeast of T0 ( $\sim 29 \mathrm{~km}$ and $\sim 65 \mathrm{~km}$, respectively), the fraction of homogenously mixed organic particles increased in both
\end{abstract}

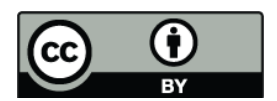

Correspondence to: M. K. Gilles (mkgilles@lbl.gov) size and number. These observations illustrate the evolution of the physical mixing state and organic bonding in individual particles in a photochemically active environment.

\section{Introduction}

Organic carbon (OC) is a large component of submicron atmospheric aerosol particles. Quantitative and qualitative analysis of organic aerosols poses substantial challenges for field measurements (Fuzzi et al., 2006) because of their small size and chemical complexity. For developing robust, physically-based models of climate change and visibility, as well as understanding aerosol environmental and health effects, a detailed understanding of aerosol organic carbon and its atmospheric processing is necessary.

OC dominates the submicron aerosol mass in many geographical locations, particularly downwind of urban sites (Zhang et al., 2007), regions with large biogenic OC sources (Geron, 2009), and areas affected by biomass burning (Reid et al., 2005). A large fraction of the OC from both anthropogenic and biogenic sources is thought to be low volatility condensed phase species that arise from photochemical oxidation of gas-phase precursors (Robinson et al., 2007; Seinfeld and Pankow, 2003). To improve our understanding of organic aerosols, field studies in photochemically active areas with large biogenic and anthropogenic organic carbon emissions are essential. 
Various techniques measure organic aerosol particles online and off-line. The most prevalent on-line techniques are bulk aerosol mass spectrometers, single particle mass spectrometers, and thermo-optical (Bae et al., 2007; Canagaratna et al., 2007; Murphy, 2007). Although these techniques are useful for quantification of bulk organic matter, they have limited application for molecular level understanding of organic aerosol. For example, bulk aerosol mass spectrometers and single particle mass spectrometers cannot identify parent molecular species due to extensive fragmentation upon ionization. Thermo-optical methods quantify elemental and organic carbon based upon instrumental definitions. In general, bulk techniques provide average properties and any information on different particle types, internally or externally mixed, is lost.

Coupled spectroscopic and microscopic methods provide elemental and molecular detail on individual particles. Transmission electron microscopy (TEM) and scanning electron microscopy (SEM) yield detailed images of the physical structure of individual particles (Laskin et al., 2006; van Poppel et al., 2005; Hopkins et al., 2008). Electron microscopy with energy dispersive X-ray (EDX) microanalysis or electron energy loss spectroscopy (EELS) yields spatially resolved chemical composition of individual particles (Alexander et al., 2008; Katrinak et al., 1992). One general limitation of EDX is that quantitative analysis of low-Z elements (carbon, nitrogen, and oxygen) is not always possible and requires time-intensive Monte-Carlo calculations (Ro et al., 2003, 2004). TEM imaging with EELS can be used to characterize carbon content of particles, but its limited energy resolution precludes detailed analysis of carbon bonding (Katrinak et al., 1992). Furthermore, high-energy electrons used in TEM and SEM may induce changes in chemical bonding (Braun et al., 2009; Egerton et al., 2004; Sayre et al., 1977). These methods produce elegant images and elemental compositions for high- $Z$ elements, but provide little information about chemical bonding or oxidation states for carbon, nitrogen and oxygen.

Scanning transmission X-ray microscopy (STXM) (Kirz and Rarback, 1985; Kilcoyne et al., 2003; Beetz et al., 2003) can acquire spatially resolved NEXAFS spectra at the carbon K-edge and was initially used for analysis of a small number of particles (Maria et al., 2004; Russell et al., 2002). Later studies have expanded to obtain more statistically representative results (Takahama et al., 2007; Hopkins et al., 2008; Hopkins et al., 2007b; Tivanski et al., 2007; Maria et al., 2004). STXM microscopy is a synchrotron technique that utilizes the "soft" X-ray radiation in the energy region of $\sim 100-1000 \mathrm{eV}$. In this region, high resolution spectral images are obtained for a detailed NEXAFS analysis at a limited spatial resolution of $\sim 25 \mathrm{~nm}$ (Kilcoyne et al., 2003). The STXM/NEXAFS technique compliments electron microscopy techniques because it provides detailed molecular speciation for carbon. Although no single technique yields a complete set of information about particle morphology, chemical bonding, and elemental composition, their combination provides a more comprehensive characterization of particles collected in the field (Hopkins et al., 2007a; Moffet et al., 2008b).

The transformation of organic aerosol in Mexico City has been extensively characterized in several field studies (Molina and Molina, 2002; Molina et al., 2007). During daylight hours, the observation of extremely active secondary organic aerosol formation was consistently observed (Volkamer et al., 2006; Salcedo et al., 2006). Although tempting to attribute most of the organic aerosol burden to automotive sources, recent findings suggest that widespread biomass burning contributes significantly to organic mass (Marley et al., 2009b; Yokelson et al., 2007; Moffet et al., 2008a). In the most recent field study, the Megacities Initiative: Local and Global Research Observations (MILAGRO) 2006, intensive measurements characterized the increase in organic mass with plume age (Doran et al., 2007, 2008; Kleinman et al., 2008). However crucial, quantifying the bulk organic mass is but a single piece of a complex puzzle. A more complete description of OC requires microscopic and molecular level speciation of organic matter within individual particles.

Here, we present detailed chemical speciation of individual particles collected at three ground sites during the MILAGRO field study. Particle analysis was accomplished using computer controlled SEM/EDX (CCSEM/EDX) and STXM/NEXAFS. Back trajectories and chemical measurements of bulk particulate matter were used to identify a period of air plume transport from the center of Mexico City (T0) to the sites located progressively further from the city (T1 and T2). Samples were chosen from this transport period for detailed microscopic analysis to provide insight into the aging of atmospheric particles.

\section{Experimental}

\subsection{Sampling sites and particle collection}

Particle samples were collected continuously at three field supersites (T0, T1, and T2) indicted in Fig. 1, during the MILAGRO 2006 study. Sites were selected based on meteorological modeling and previous field measurements that indicated prevailing flows from T0 to T2 (Doran et al., 1998). The sampling times, locations, elevations, and relative humidities are summarized in Table 1. At T0, particle samples were collected at the rooftop of a five story building $\sim 20 \mathrm{~m}$ above the ground. T0 was an industrial/residential neighborhood in the northern part of Mexico City surrounded by heavy vehicular traffic. The T1 site, located at the Technological University of Tecamac, was surrounded by farmland, commercial, and residential areas. The $\mathrm{T} 2$ site, at the Rancho la Bisnaga, was a rural site surrounded by farmland.

At all three sites, particle samples were collected using compact Time Resolved Aerosol Collectors (TRAC) (Laskin 
Table 1. Summary of the sampling sites, times, locations and relative humidity.

\begin{tabular}{clllll}
\hline Site Name & $\begin{array}{l}\text { Sampling Time } \\
\text { (CST) }\end{array}$ & Location & $\begin{array}{l}\text { Elevation } \\
(\mathrm{m})\end{array}$ & $\begin{array}{l}\text { Relative } \\
\text { Humidity } \\
(\%)\end{array}$ & $\begin{array}{l}\text { Max. } \\
\text { Relative } \\
\text { Humidity } \\
(\%)\end{array}$ \\
\hline T0 & $12: 30-12: 45$ & $\begin{array}{l}19^{\circ} 29^{\prime} 233.60^{\prime \prime} \mathrm{N} \\
99^{\circ} 08^{\prime} 55.60^{\prime \prime} \mathrm{W}\end{array}$ & 2240 & 31 & 72 \\
$\mathrm{~T} 1$ & $13: 00-13: 15$ & $\begin{array}{l}19^{\circ} 42^{\prime} 12.41^{\prime \prime} \mathrm{N} \\
98^{\circ} 58^{\prime} 59.12^{\prime \prime} \mathrm{W}\end{array}$ & 2273 & 30 & 90 \\
$\mathrm{~T} 1$ & $18: 00-18: 15$ & & 40 & \\
$\mathrm{~T} 2$ & $14: 30-14: 45$ & $20^{\circ} 0^{\prime} 35.81^{\prime \prime} \mathrm{N}$ & 2542 & 33 & 88 \\
$\mathrm{~T} 2$ & $19: 30-19: 45$ & $98^{\circ} 54^{\prime} 32.37^{\prime \prime} \mathrm{W}$ & & 64 & \\
\hline
\end{tabular}

${ }^{\dagger}$ RH values reported in Marley et al. (Marley et al., 2009a).

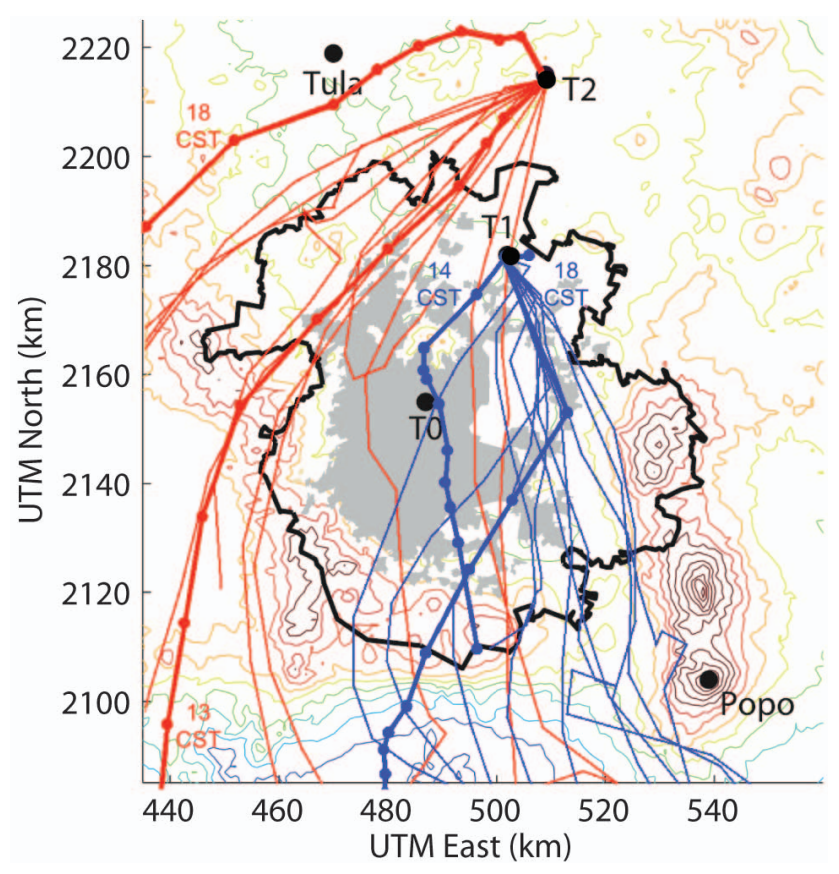

Fig. 1. A map of the Mexico City area. The MCMA political border is represented by the black line and the urban area is shaded in grey. The colored lines are terrain contours every $250 \mathrm{~m}$. The location markers with black dots are the T0-T2 sampling sites, Tula refinery, and Popocatepetl volcano. Blue and red lines indicate $12 \mathrm{~h}$ backtrajectories ending at the $\mathrm{T} 1$ and $\mathrm{T} 2$ sampling sites, respectively, on every hour over the period of 06:00-18:00 CST on 22 March 2006. Dots on the thick lines denote positions at hourly intervals for select trajectories.

et al., 2006; Laskin et al., 2003). The TRAC samplers deposited particles onto prearranged microscopy substrates that were automatically replaced every $15 \mathrm{~min}$. Bulk particulate matter was continuously collected onto Teflon strips using a three-stage Davis Rotating drum Universal size-cut Monitor- ing (DRUM) impactor (Cahill and Wayakabashi, 1993). After collection, the exposed substrates were sealed and stored pending analyses.

\subsection{Sample selection based upon meteorological data}

After an initial analysis of the field data (Doran et al., 2007; de Foy et al., 2008), a specific time period was chosen for a detailed analyses - 22 March 2006. During that day, the northeastern airflow was from T0 to T2. The Weather Research and Forecasting (WRF) model reproduced the local, regional, and synoptic meteorological conditions (Fast et al., 2009). The predicted meteorological conditions were constrained by employing a four-dimensional data assimilation technique in WRF using the available radar wind profiler and radiosonde measurements. Figure 1 shows $12 \mathrm{~h}$ back trajectories for each hour between 06 and 18 local time (CST) at $\mathrm{T} 1$ and $\mathrm{T} 2$. These were computed using a Lagrangian particle dispersion model (Doran et al., 2008; Fast and Easter, 2006). The trajectories indicate that the sampled air mass from Mexico City advected northeast toward T1 and T2. The travel time of the urban air plume from T0 to T1 and T2 was approximately 3 and $6 \mathrm{~h}$, respectively. These times are consistent with estimates of the median transport periods from T0 to T1 (between 2 to $4 \mathrm{~h}$ ) and T2 (between 4 to $10 \mathrm{~h}$ ) (Doran et al., 2008). During this sampling period, the surface air temperature increased from $\sim 12 \mathrm{C}$ at sunrise to $\sim 26 \mathrm{C}$ by mid-afternoon. The maximum mixed layer height after 14:00 CST was between 2.5 and $3.0 \mathrm{~km}$ above ground level at T0 and T1, but was $\sim 0.5 \mathrm{~km}$ higher at T2 (Shaw et al., 2007).

\subsection{Methods of laboratory analyses}

In this work, analyses of the particle samples using four analytical techniques are presented: (1) Proton Induced $\mathrm{X}$-ray emission (PIXE) provided elemental concentrations 
for time-resolved particulate matter samples collected by the DRUM sampler; (2) Synchrotron X-ray Fluorescence (SXRF) analysis provided additional confirmation of timeresolved elemental analysis; (3) CCSEM/EDX provided imaging of individual particles and quantitative elemental compositions; (4) STXM/NEXAFS provided speciation of the carbonaceous content and its radial distribution within individual particles.

\subsubsection{Proton Induced X-ray emission}

PIXE analyses of the DRUM collected samples were carried out within several weeks following the MILAGRO 2006 field campaign at the Environmental Molecular Sciences Laboratory (EMSL) located at the Pacific Northwest National Laboratory (PNNL). Detailed experimental procedures are described elsewhere (Johnson et al., 2006; Shutthanandan et al., 2002). Briefly, PIXE analyses were performed under vacuum $\left(2 \times 10^{-7}\right.$ Torr $)$ with a $3.5 \mathrm{MeV}$ proton beam. The resulting PIXE spectra were evaluated using the GUPIX program (Maxwell et al., 1989), and mass concentrations of elements were calibrated to known standards with a $5 \%$ uncertainty. The final results are reported as time series (mass per volume of air sampled) with a resolution of $6 \mathrm{~h}$.

\subsubsection{Synchrotron X-ray Fluorescence (SXRF) analysis}

Using the same samples as for the PIXE analysis, elemental concentrations were also obtained with Synchrotron X-Ray Fluorescence (SXRF) analysis. The SXRF data allowed for a quality control of the PIXE data. Details of the SXRF analysis are described elsewhere (cf. Perry et al., 2004). The SXRF analysis was performed using beamline 10.3.1 at the Advanced Light Source (ALS) at Lawrence Berkeley National Laboratory. The beamline 10.3.1 X-ray microprobe is designed to operate at photon energies over the range from 1.5 to $18.5 \mathrm{keV}$ using a white (i.e., nonmonochromatic) beam configuration. This energy range permits quantitative analysis of the elements sodium through uranium for samples under vacuum. The beam is collimated to a $500 \mu \mathrm{m}$ by $500 \mu \mathrm{m}$ spot resulting in a temporal resolution of $3 \mathrm{~h}$ and thus, allowed elemental characterization of transported plumes. Previous tests have shown that the sample deposited from the drum impactor is extremely uniform across sample deposition spot (Bench et al., 2002). Deconvolutions of the raw X-ray spectra are performed using WinAXIL (Canberra). Quantitative analysis is performed by calibrating the response of the system to a comprehensive set of 40 singleelement and multielement NIST-traceable standards (Micromatter, Inc.).

\subsubsection{Scanning electron microscopy}

A FEI XL30 digital field emission gun environmental scanning electron microscope at EMSL/PNNL was used for CCSEM/EDX analysis of the particle samples collected by
TRAC on filmed TEM grids (Copper 400 mesh grids, Carbon type B film, Ted Pella, Inc.). During the analyses, particles were automatically inspected and their contours recognized by an increase in the detector signal above a threshold level. The instrument then acquired an X-ray spectrum for each detected particle. Additionally, line scans were carried out by scanning the electron beam through the center of the particle while recording the EDX spectrum. In this work, the EDX analysis was limited to particles with an equivalent circular diameter larger than $0.2 \mu \mathrm{m}$. The X-ray spectra were acquired for $10 \mathrm{~s}$, at a beam current of $\sim 500 \mathrm{pA}$ and an accelerating voltage of $20 \mathrm{kV}$. The elements considered in the analysis were $\mathrm{C}, \mathrm{N}, \mathrm{O}, \mathrm{Na}, \mathrm{Mg}, \mathrm{Al}, \mathrm{Si}, \mathrm{P}, \mathrm{S}, \mathrm{Cl}, \mathrm{K}, \mathrm{Ca}, \mathrm{Ti}, \mathrm{Mn}, \mathrm{Fe}$, $\mathrm{Ni}, \mathrm{Cr}, \mathrm{Zn}$, and $\mathrm{Pb}$. The atomic percent data for $\mathrm{C}, \mathrm{O}$, and $\mathrm{N}$ are regarded as semi-quantitative, due to contributions from the thin film substrate as well as other experimental complications. Additional details of the CCSEM/EDX analysis of particles deposited onto filmed grid substrates are described elsewhere (Laskin et al., 2006), and references therein.

\subsubsection{Scanning transmission X-ray microscopy}

STXM/NEXAFS analyses of the same TRAC samples were conducted at the ALS. The STXM instrument has been previously described (Kilcoyne et al., 2003), therefore only a brief description is presented here. Soft X-ray radiation is produced in the synchrotron using either a bending magnet (beamline 5.3.2) or an elliptically polarizing undulator (beamline 11.0.2). Both beamlines cover the energy ranges characteristic of $\mathrm{C}(290 \mathrm{eV}), \mathrm{N}(403 \mathrm{eV})$, and $\mathrm{O}(535 \mathrm{eV})$ absorption edges. Beamline 11.0.2 also covers the energy range for $\mathrm{S}(170 \mathrm{eV})$. The $\mathrm{X}$-ray energy was selected with a monochromator. A Fresnel zone plate then focused the X-ray beam to a small $(\sim 25-35 \mathrm{~nm})$ spot. To obtain an image at a fixed energy, piezoelectric nano-translators scanned the sample at the focal point of the X-ray beam while the transmitted intensity $(I)$ was measured. The energy was then stepped and the sample scanned again for a series of energies (typically $\sim 110$ steps for a carbon K-edge spectrum) to obtain a "stack" of spectral images. The X-ray spectrum was converted to optical density (OD) by measuring $\left(I_{0}\right)$ through a particle free region of the sample and using the relation OD = $\ln \left(I_{0} / I\right)=\mu \rho \mathrm{t}$, where $\mu$ was the mass absorption coefficient, $\rho$ was the mass density, and $t$ was the material thickness. CCSEM/EDX and STXM/NEXAFS analyses were carried out over different sample regions to mitigate radiation damage from prior exposure. This is particularly important for the STXM/NEXAFS measurements that explicitly examine chemical bonding. Particles smaller than $100 \mathrm{~nm}$ were not considered for analysis. 


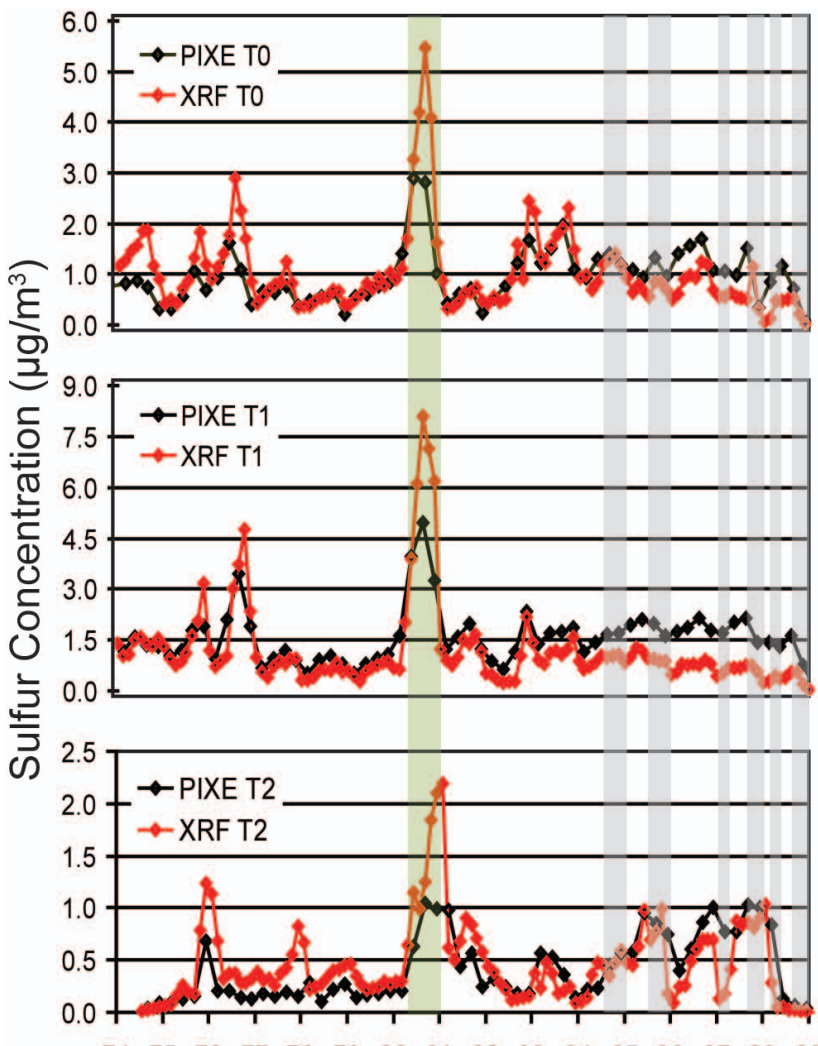

$\begin{array}{llllllllllllllll}74 & 75 & 76 & 77 & 78 & 79 & 80 & 81 & 82 & 83 & 84 & 85 & 86 & 87 & 88 & 89\end{array}$

Fig. 2. Time series of the particulate Sulfur mass concentrations at the three sampling sites T0, T1, and T2 measured by PIXE and synchrotron XRF. Starting with T0, each site was located progressively farther from the Mexico City center. During the day of transport 22 March 2006 (DOY 80) large sulfur concentrations were observed at all three sites, indicating effective capture of the transport plume by particle samples. Additional transport days are indicated with the gray bars.

\section{Results and discussion}

\subsection{Confirmation of the transport event of 22 March 2006 via elemental analysis}

During the MILAGRO study, meteorological measurements and modeling data indicated several days when aerosols originating in Mexico City passed through T1 and T2 (Doran et al., 2007). The PIXE and SXRF data confirmed that particles from a regional plume were sampled and aided in selecting a specific transport day for detailed particle analyses. The sulfur time series determined by PIXE and SXRF for the three sites on 22 March 2006 (DOY 80) are shown in Fig. 2. At every site, the data sets contained strong sulfur peaks which indicate a heavily polluted air mass. During 22 March, the total $\mathrm{PM}_{2.5}$ mass concentration at T0 $\left(252 \mu \mathrm{g} / \mathrm{m}^{3}\right)$ was the second highest value of the campaign (de Foy et al., 2008). Collocated aerosol mass spectrometry measurements suggest that organics accounted for the majority of the non-refractory mass during this time (Aiken et al., 2009). Typically, sulfates and organics, coupled with the high altitude of Mexico City ( $\sim 2200 \mathrm{~m}$ ), should provide ideal conditions for secondary aerosol production. However, $\mathrm{O}_{3}(125 \mathrm{ppb})$ and $\mathrm{SO}_{2}$ (32 ppb) maximum concentrations were not abnormally high on this day (de Foy et al., 2008). Air mass back trajectories (not shown) indicate that sulfate and organics from the Tula refinery complex (located $\sim 112 \mathrm{~km}$ north of T0) were carried in the morning air flow to $\mathrm{T} 0$, and subsequently flowed from $\mathrm{T} 0$ to $\mathrm{T} 1$ and $\mathrm{T} 2$. Therefore, the morning aerosol at T0 most likely contained a mixture of fresh emissions and transported aged emissions from Tula. Presumably, the mixture further evolved during transport to $\mathrm{T} 1$ and $\mathrm{T} 2$.

\subsection{Single particle analysis}

\subsubsection{SEM analysis}

Typical SEM images from all three sites are shown in Fig. 3. In all samples, a visible coating surrounding the particle cores was observed. This coating was attributed to photochemically formed secondary organic material. To confirm the organic nature of the coating, EDX line scans were performed. X-ray line scans over particles from $\mathrm{T} 0$ are shown in Fig. 4a. In Fig. 4a, arrows indicate the positions and directions of line scans on the corresponding SEM image. Xray signals from carbon, sulfur, and potassium along the line scans are shown in panels (b) and (c). The line scans indicate the highest carbon concentrations occur at the particle edges and that sulfur and potassium are enhanced at the particle cores. The data suggest the particle cores are composed of sulfates that are surrounded by carbonaceous material. Based on the ambient RH $(<71 \%$, Table 1$)$ and density measurements made at T0 (Moffet et al., 2008c), particles collected at T0 were in the non-hydrated state. Therefore, for Fig. 4, the crystalline morphology observed in the SEM is expected to be representative of particles in the ambient atmosphere. Although to a lesser extent, potassium (which may indicate contributions from biomass burning or cooking emissions) is also concentrated at the particle cores. The CCSEM/EDX analysis provides quantitative data on the elemental composition and size of individual particles. However, CCSEM/EDX measurements (other than line scan mode) probe the entire particle and provide no information on a particle's internal structure.

\subsection{STXM/NEXAFS analysis}

To further probe particle's internal structure, carbon K-edge spectral maps from the STXM/NEXAFS analysis were obtained. Carbon K-edge spectra and maps shown in Fig. 5 were obtained by singular value decomposition (Koprinarov et al., 2002) using three components: 1) inorganic (IN), 2) organic carbon (OC), and 3) elemental carbon (EC). The three chemically uniform and distinct particle regions (EC, OC, 

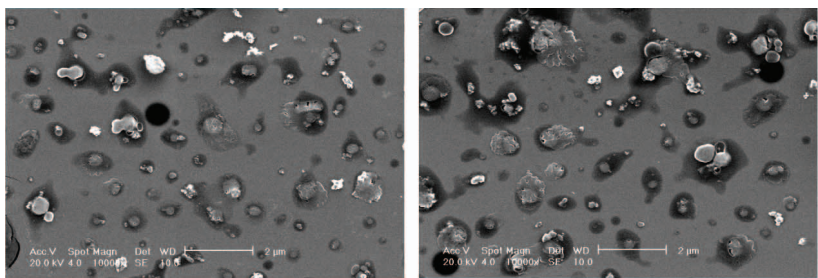

T0 12:35 CST
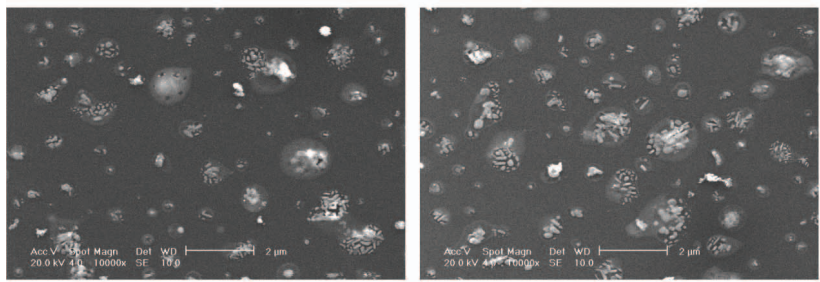

T1 14:00 CST

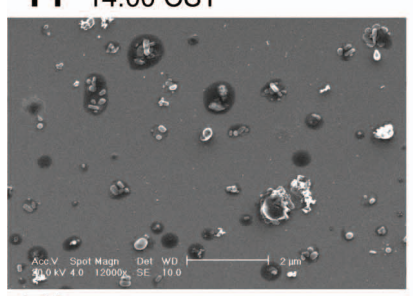

T1 19:00 CST

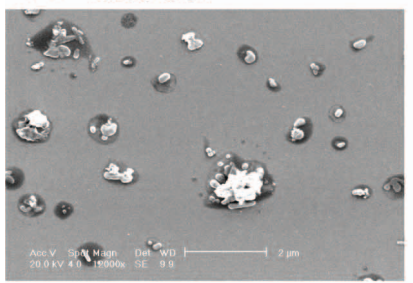

T2 $14: 30$ CST

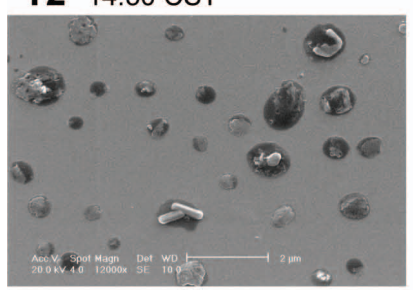

T2 19:30 CST

Fig. 3. SEM images of typical particles collected during the transport event of 22 March 2006 at three sites.

and IN) are referred to as phases throughout the remainder of this manuscript. The methodology employed to map phases and assess internal mixing in individual particles using automated processing of the STXM/NEXAFS data is described in a separate manuscript (Moffet et al., 2010). Figure 6 shows representative sulfur, nitrogen and oxygen K-edge spectra for these phases for T0, T1, and T2. Heterogeneous structure was observed in many particles from T0. However, T1 and T2 had larger, more homogenously mixed organic particles. Most often, EC was surrounded by organics. However, occasionally fresh (uncoated) EC was observed. This will

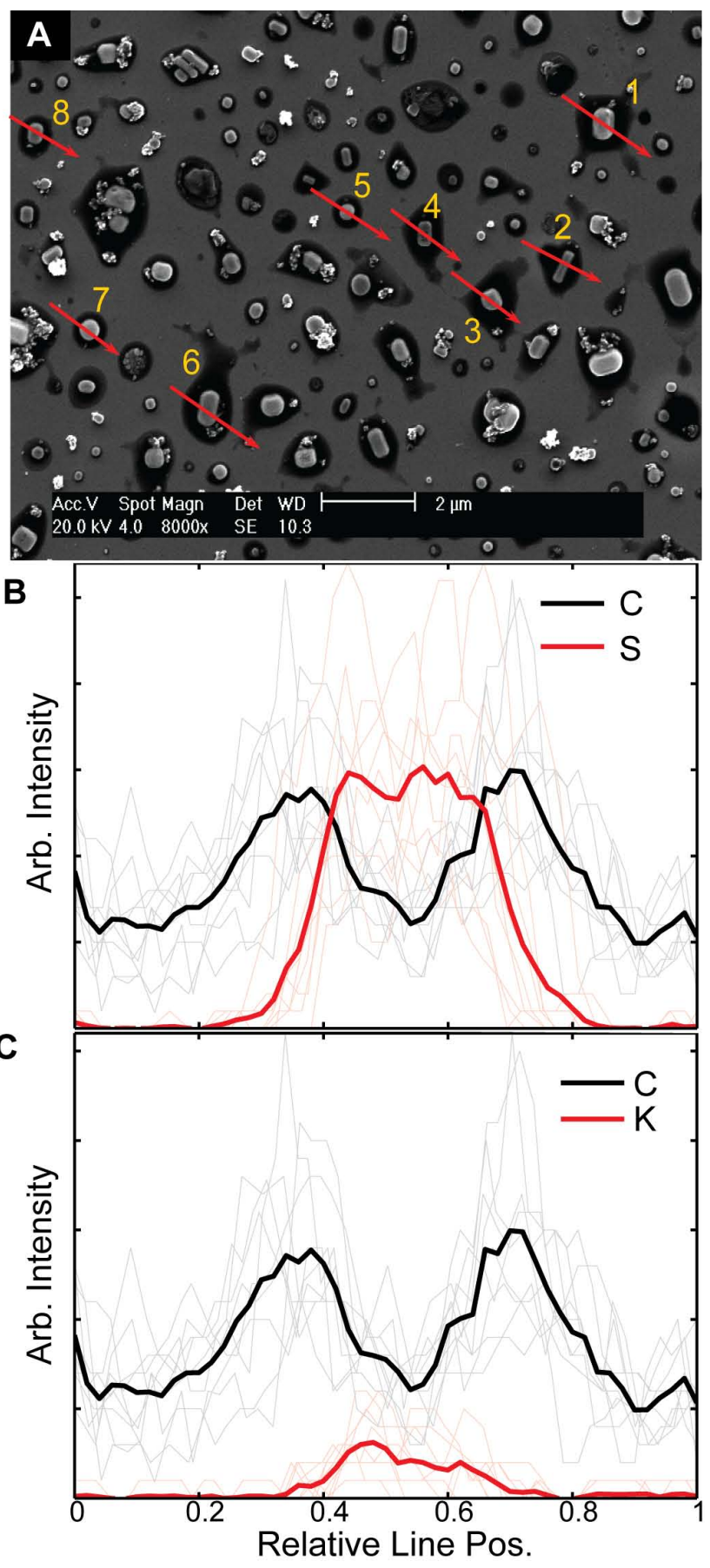

Fig. 4. SEM image together with carbon, sulfur and potassium linescans for particles from T0 site. The locations and directions of line scans are shown by the arrows in panel (A). The intensities of characteristic X-rays along the line scans are shown in panels $(\mathbf{B})$ and $(\mathbf{C})$. The line scans confirm that particle cores contain $\mathrm{S}$ and $\mathrm{K}$, coated by carbonaceous material. $\mathrm{X}$ axis was normalized by the total scan distance. The bold lines represent the X-ray intensities averaged for a number of individual line scans represented by faint lines. 

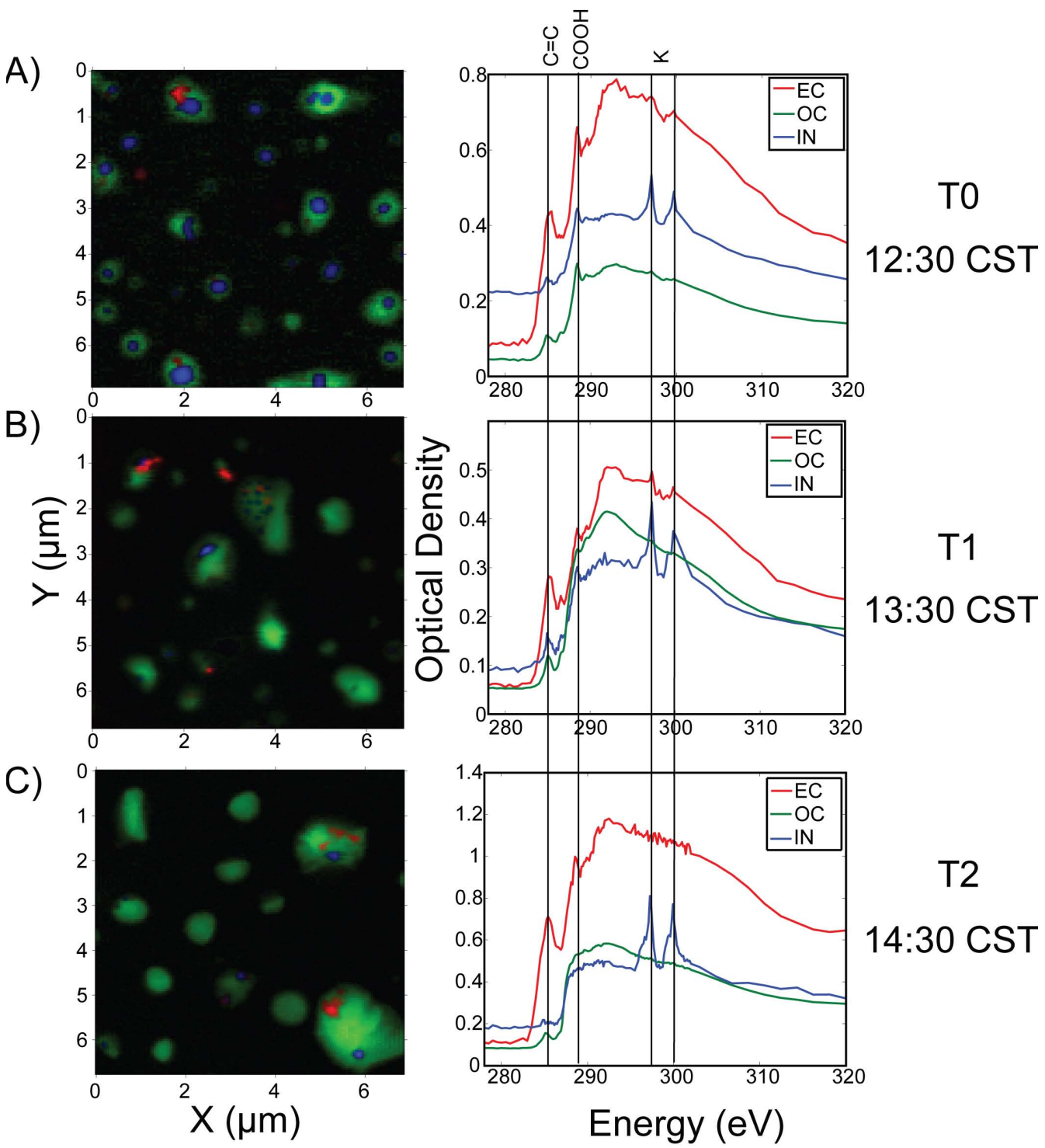

Fig. 5. Particle maps produced by singular value decomposition of carbon K-edge spectral image "stacks" from STXM/NEXAFS. Spectra on the right show components used to obtain the component maps on the left. This was done for (A) T0 at 12:30, (B) T1 at 13:30 and T2 at 14:30. For every ambient sample three major components are usually identified: 1) optically thick inorganic phase (IN) that often contains $\mathrm{K}$ - blue color, 2) Organic/secondary carbon (OC) - green color, 3) High sp ${ }^{2}$ functional hybridization, usually from elemental carbon (EC) - red color.

be more extensively quantified in a forthcoming publication. The mixing of EC and IN phases was similar for the T1 and $\mathrm{T} 2$ sites (Fig. $5 \mathrm{~b}-\mathrm{c}$ ), whereas at the $\mathrm{T} 0$ the particle centers were dominated by large IN inclusions (Fig. 5a). For the T0 particles, the EC inclusions may have been displaced from the center of the particle upon crystallization of the IN phase. In the following discussion, the chemical speciation in each of the three phases is investigated based on the spectra displayed in Figs. 5 and 6.

The IN phase (blue) in Fig. 5 has a C K-edge spectrum with a larger pre-edge $(<280 \mathrm{eV})$ baseline absorption level than total carbon absorption $(320 \mathrm{eV})$ and/or characteristic potassium peaks at 297.1 and $299.7 \mathrm{eV}$. The high pre-edge level of the inorganic region is due to a dominant density of elements other than C. For a region to be classified as IN its spectrum either contained potassium or the pre-edge intensity (absorption at $278 \mathrm{eV}$ ) was greater than half of the absorption due to carbon (absorption at $320 \mathrm{eV}$ - absorption at $280 \mathrm{eV}$ ) (Moffet et al., 2009). As particles develop thick coatings, some inorganic cores may become masked. NEXAFS spectra from the IN phase at the $\mathrm{S}, \mathrm{N}$, and $\mathrm{O}$ edges are shown in blue in Fig. 6. The carboxyl functionality observed in the OC phases (peak at $531.8 \mathrm{eV}$ in the oxygen spectrum), was small or absent in the IN phase. The $\mathrm{S}, \mathrm{O}$, 


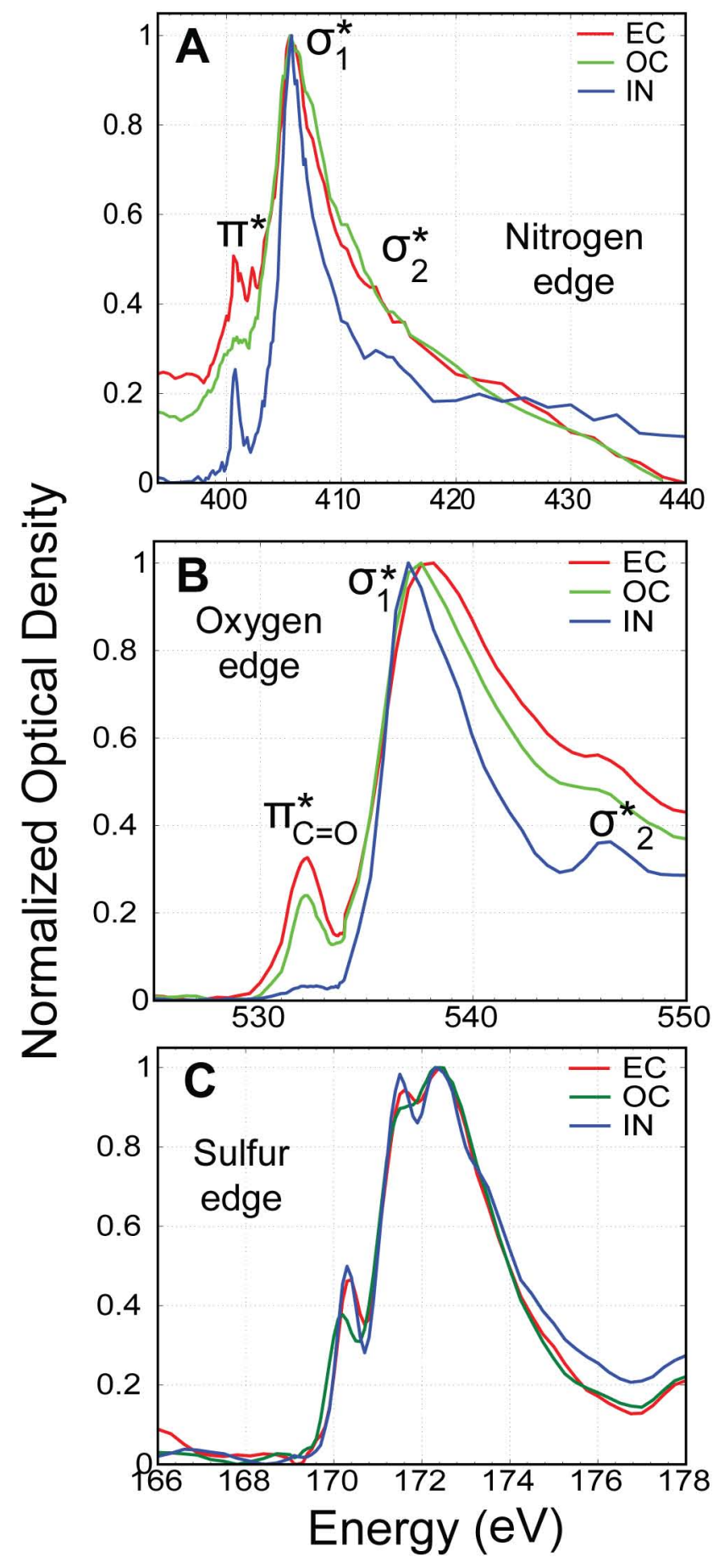

Fig. 6. Representative N, O and S edge spectra for EC, OC and Inorganic (IN) phases.

and N NEXAFS spectra of the IN phase closely resemble standard spectra of $\left(\mathrm{NH}_{4}\right)_{2} \mathrm{SO}_{4}$ (Hopkins et al., 2008). The significant $\mathrm{N} 1 \mathrm{~s} \rightarrow \pi^{*}$ peak in the IN phase (Fig. 6a) could arise from nitrates, or if the chemical species is $\left(\mathrm{NH}_{4}\right)_{2} \mathrm{SO}_{4}$, this peak could result from radiation damage. Previous stud- ies on $\left(\mathrm{NH}_{4}\right)_{2} \mathrm{SO}_{4}$ by our group indicate the $\mathrm{N} 1 \mathrm{~s} \rightarrow \pi *$ peak intensity increases with exposure to $\mathrm{X}$-ray radiation. The abundance of $\mathrm{S}$ and $\mathrm{N}$ was typically higher in the IN phase than in the OC or EC phases, consistent with the SEM/EDX results in Fig. 4 for T0.

In Fig. 5, the OC phase (green) is characterized by a dominant contribution from the $\mathrm{C} 1 \mathrm{~s} \rightarrow \pi^{*} \mathrm{COOH}$ transition $(288.5 \mathrm{eV})$ and was used to identify OC. A smaller contribution from the $\mathrm{C} 1 \mathrm{~s} \rightarrow \pi^{*} C=C$ peak at $285 \mathrm{eV}\left(\mathrm{C}=\mathrm{C}, \mathrm{sp}^{2}\right.$ hybridized carbon) is present in the $\mathrm{OC}$ phase as well. The $\mathrm{COOH}$ functionality was verified by the presence of a pronounced peak at $531.8 \mathrm{eV}$, arising from the $\mathrm{O} 1 \mathrm{~s} \rightarrow \pi^{*} C=O$ transition (green trace in Fig. 6b). Based on the S NEXAFS spectrum, (shown as the green trace of Fig. 6c) the OC phase also contains inorganic sulfur species. The sulfur spectrum measured for the OC phase resembles that previously measured in our laboratory for $\left(\mathrm{NH}_{4}\right)_{2} \mathrm{SO}_{4}$. However, the SEM/EDX line scans in Fig. 4b indicate lower sulfur concentrations in the OC phase than the IN phase. Also, the intensity of the $\mathrm{N} 1 \mathrm{~s} \rightarrow \pi *$ transition has a smaller contribution in the OC phase than in the IN phase. This indicates a difference in nitrogen speciation between the two phases. If multiple nitrogen containing compounds were present in the OC phase, the electronic transitions occurring at slightly different energies could result in overlapping features that would broaden the observed peak. This is significantly different than the well-ordered inorganic, presumably crystalline constituents, present in the IN phase. The nitrogen containing organics have been reported at $\mathrm{T} 0$ as well as in laboratory examinations of T0 particulate matter (Moffet et al., 2008a).

From the maps in Fig. 5, the organic rich particles (green) are larger and more homogenous at the rural sites (T1 and T2) than at the city center (T0). Radial scans on particles containing inorganic inclusions (as identified below), show the distribution of carboxylic acids within single particles. Figure 7 displays box whisker plots from single particle $\mathrm{COOH}$ radial scans for each sampling site, T0, T1, and T2. The radial scans were produced according to Takahama et al. (2008), except $\mathrm{COOH}$ was calculated as the difference between the intensity of the $\mathrm{C} 1 \mathrm{~s} \rightarrow \pi^{*} \mathrm{COOH}$ transition and the pre-edge intensity. At T0, $\mathrm{COOH}$ is depleted at the particle center due to the presence of large inorganic inclusions. This is contrary to the radial scans of particles with inorganic inclusions from $\mathrm{T} 1$ and $\mathrm{T} 2$, most of which have the highest $\mathrm{COOH}$ peak intensity at the particle centers. This indicates the physical mixing of organic material within particulates differs among the urban site (T0) and the rural sites (T1, T2).

In the map in Fig. 5, carbon-carbon $\mathrm{sp}^{2}$ bonds $(\mathrm{C}=\mathrm{C})$ rich particle regions are indicated by red with the corresponding spectra also shown in red. The abundance of $\mathrm{sp}^{2}$ hybridized $\mathrm{C}=\mathrm{C}$ bonds, characterized by the large peak at $285 \mathrm{eV}$, is correlated with the presence of EC (Hopkins et al., 2007b). At the carbon edge, the increased absorption of soot relative to organics arises from the higher material density of black carbon $\left(\sim 1.8 \mathrm{~g} / \mathrm{cm}^{3}\right)$ versus organic carbon $\left(\sim 1 \mathrm{~g} / \mathrm{cm}^{3}\right)$. For a 


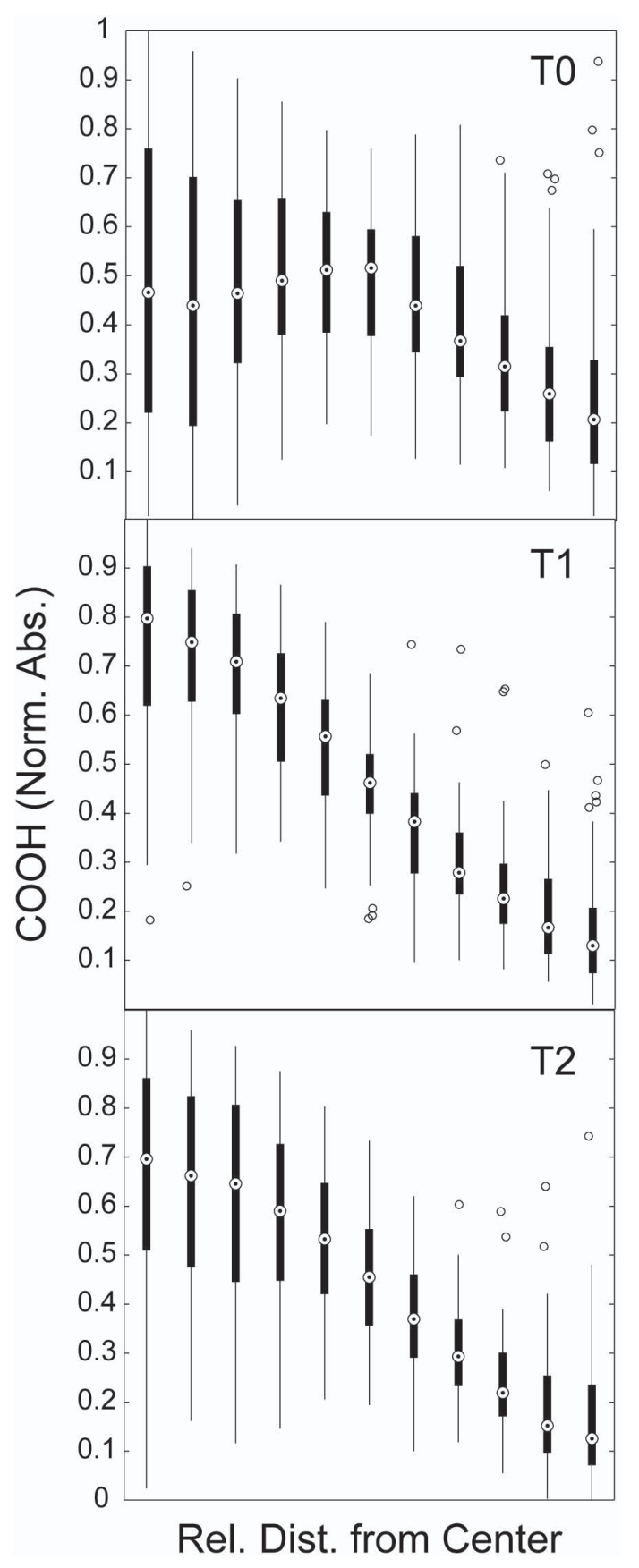

Fig. 7. COOH radial scans from STXM/NEXAFS analysis of particles having inorganic inclusions. At the urban site (T0), the inorganic inclusions were located at the center of the particle, resulting in a lower $\mathrm{COOH}$ content at that location of the particle. At $\mathrm{T} 1$ and $\mathrm{T} 2$, the inorganic material was typically not located at the center of the particles as indicated by the fact that the $\mathrm{COOH}$ absorption was highest there. The mean value is indicated by the central white circle with black dot. The boxes represent the 25 and 75 th percentiles and the whiskers extend to the most extreme datapoints. The individual unfilled circles are outliers.

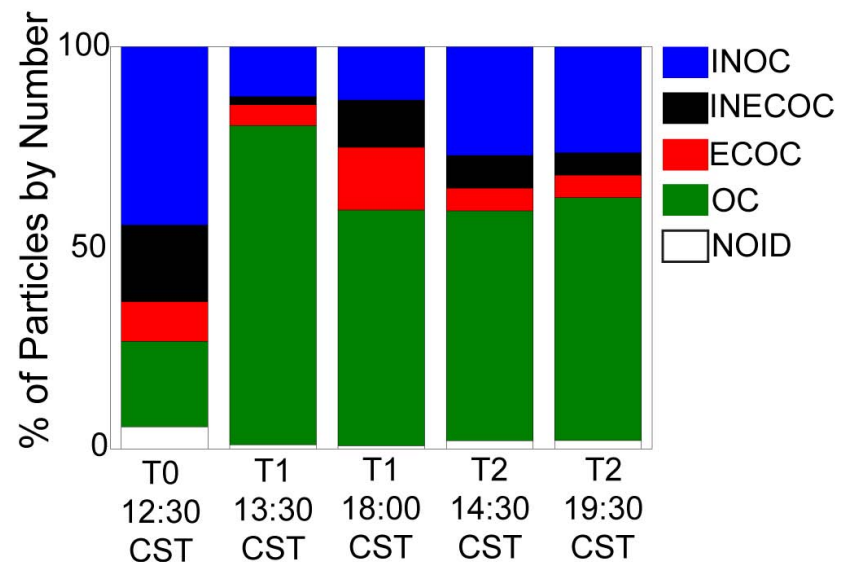

Fig. 8. Fractions of particle types identified by the STXM/NEXAFS analyses and defined in Fig. 3 for the samples collected at different sampling sites. NOID indicates the particles that were not identified.

particle region to be labeled as $\mathrm{EC}$, the $\% \mathrm{sp}^{2}$ was empirically set at $35 \%$. It is possible that some of the EC phase can be masked by a thick organic coating. EC inclusions observed in this study appear as either compact structures or non-spherical fractal-like structures. In samples from Mexico City, the spectra of particles containing EC have a significant $\mathrm{COOH}$ peak. This was not observed in soot from diesel exhaust or standard black carbon materials (Hopkins et al., 2007b) and is attributed to the high photochemical activity of Mexico City. In Fig. 6b, the oxygen edge spectrum for the EC particles, like the OC phase, has a pronounced peak at $531.8 \mathrm{eV}$ verifying the carbonyl $(\mathrm{C}=\mathrm{O})$ functionality (Lessard et al., 2007; Urquhart and Ade, 2002). This observation is consistent with the observation that double bonds of soot (EC) readily undergo oxidation reactions to form carbonyl groups (Nienow and Roberts, 2006).

\subsection{Evolution of particle chemical composition}

Carbon K edge spectra were measured on samples from each site and the three phases (IN, OC, EC) were mapped. Combinations of these phases were used to quantify the particle mixing state transformation from $\mathrm{T} 0$ to $\mathrm{T} 2$. To ascertain the changes in mixing state as particles were transported away from the city center, rule-based classifications defined particle phase mixing. Particles detected in the MILAGRO samples from 22 March 2006 were sorted in four major groups based upon the phases present within individual particles: INOC, INOCEC, ECOC, and OC. The OC phase was present in all particles and is included in each group.

In Fig. 8 the relative fraction of the particle classes at each sampling site is shown. The number of particles analyzed in each sample ranged between 130 and 320. The least populated class ( 9 particles) had an uncertainty of $33 \%$ due to counting statistics. As illustrated in Fig. 8, the fraction of 


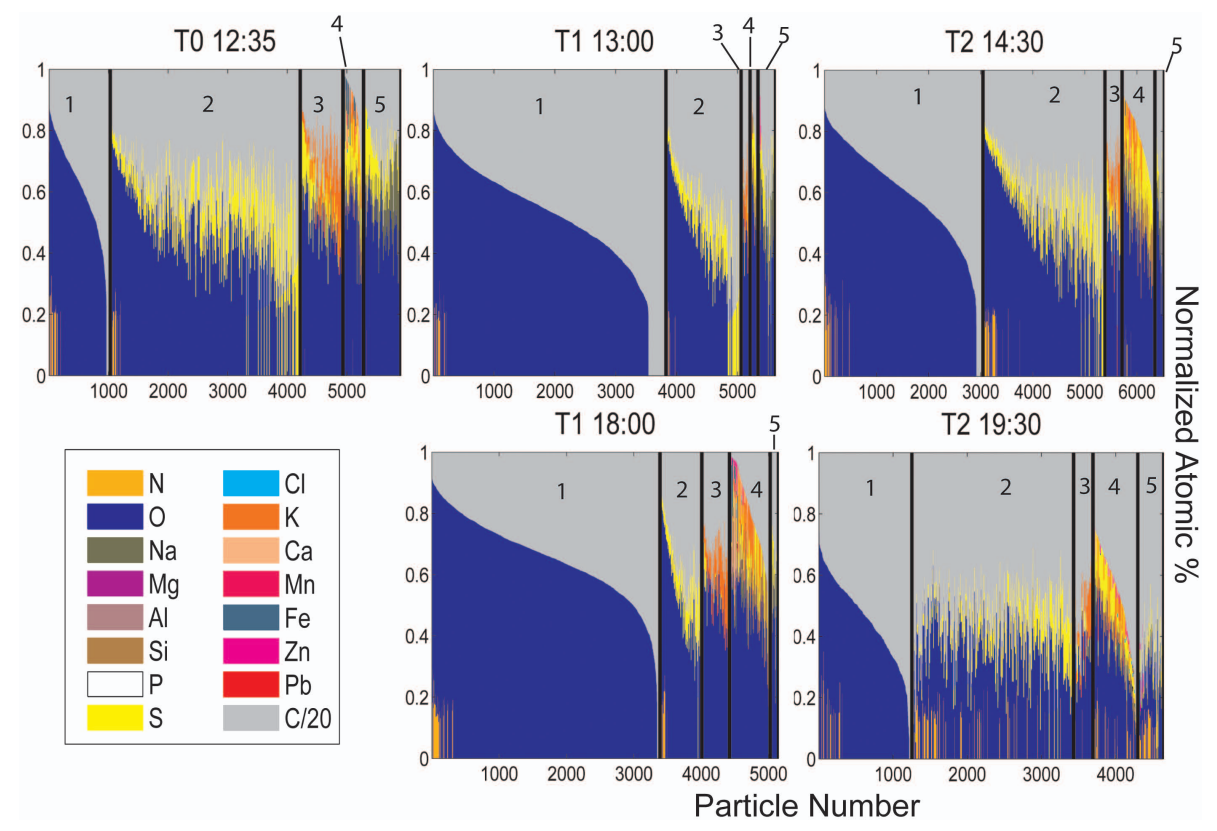

Fig. 9. Bar plot presentation of CCSEM/EDX data indicating composition of individual particles (each plot shows 5000-7000 particles) and relative particle-type contributions to the total sample characteristic for each of the samples collected at three sampling sites. Particle types are as follows: 1) CNO 2) CNOS 3) CNOSKNa 4) mineral dust 5) NaRich.

homogenous OC particles (green) is much greater at $\mathrm{T} 1$ and $\mathrm{T} 2$ than $\mathrm{T} 0$. This increase in homogeneous OC particles may be related to the high sulfur concentrations, hydration histories, condensational growth, or the influence of local sources. The most probable reason for the increase in homogenous OC particles is the growth of nucleation mode particles. If organics and sulfate condensed simultaneously during this growth, they would be well-mixed and appear as homogenous particles, particularly if the aerosols have not undergone a deliquescence/efflorescence cycle. The inhomogeneous INOC particles with large central IN inclusions may be from a source specific to T0. The inorganic inclusions for $\mathrm{T} 1$ and $\mathrm{T} 2$ were typically smaller and not as centrally located compared to the particles at T0. Particles at T0 bear a resemblance to particles obtained from sampling grass fires (Li et al., 2003; Posfai et al., 2003). Such fires were observed at T0 during this time of day and produced particles with a similar composition (organics and potassium) (Moffet et al., 2008a). Smaller inorganic inclusions at T1 and T2 could result from a different formation process (i.e. secondary condensation) than that responsible for formation of the large inorganic crystals at $\mathrm{T} 0$.

The CCSEM/EDX analysis provides additional evidence that the fraction of the predominantly organic containing particles increases in T1 and T2 samples. Figure 9 shows single particle stacked bar plots for each sample. Each bar represents the composition of a single particle; the colors indicate the relative atomic percent of the element indicated in the legend. Consistent with the STXM/NEXAFS results, the fraction of particles containing only carbon, nitrogen and/or oxygen increases from $\mathrm{T} 0$ to $\mathrm{T} 1$ and $\mathrm{T} 2$. These data show particles at T0 $(\sim 50 \%)$ that are rich in sulfur. The highest fraction of particles containing $\mathrm{Na}$ and $\mathrm{K}$ are also seen at T0, a finding consistent with the large number of biomass sources, and industrial emissions in the city center (Adachi and Buseck, 2008; Moffet et al., 2008a; Aiken et al., 2009). The Na rich particles identified by CCSEM/EDX were internally mixed and composed of only $\mathrm{S}, \mathrm{Cl}, \mathrm{N}$, and $\mathrm{O}$, suggesting a non-mineral dust origin. In contrast, the rural $\mathrm{T} 1$ and $\mathrm{T} 2$ sites have a higher fraction of mineral dust particles containing the elements $\mathrm{Al}, \mathrm{Si}, \mathrm{Ca}$ and $\mathrm{Fe}$. The $\mathrm{Na}$ rich particles may arise due to the close proximity of T0 to the dry lake bed, Texcoco (Moffet et al., 2008a).

Additional insight into the source of the homogenous OC particles is gained by analyzing the size distributions of different particle types. Figure 10 illustrates chemically-resolved particle size distributions obtained from STXM/NEXAFS (left panels) and CCSEM/EDX (right panels). As shown in Fig. 10, both the abundance and size of the OC particles increase from $\mathrm{T} 0$ to $\mathrm{T} 1$ and $\mathrm{T} 2$. Because the sampling sites are spatially and temporally separated, the homogenous OC particles could increase in size during transport as implied by Fig. 10. Other investigators have shown that condensational growth of Aitken mode particles was the main mechanism by which aerosol concentrations increased during aging in Mexico City (Iida et al., 2008; Kleinman et al., 2009). In particular, Iida et al. (2008) show a similar nucleation event occurring at T1 for 22 March 2006. At the $\mathrm{T} 1$ site, Smith et al. noted that the nucleation mode particles were dominated by organics (Smith et al., 2008). These 

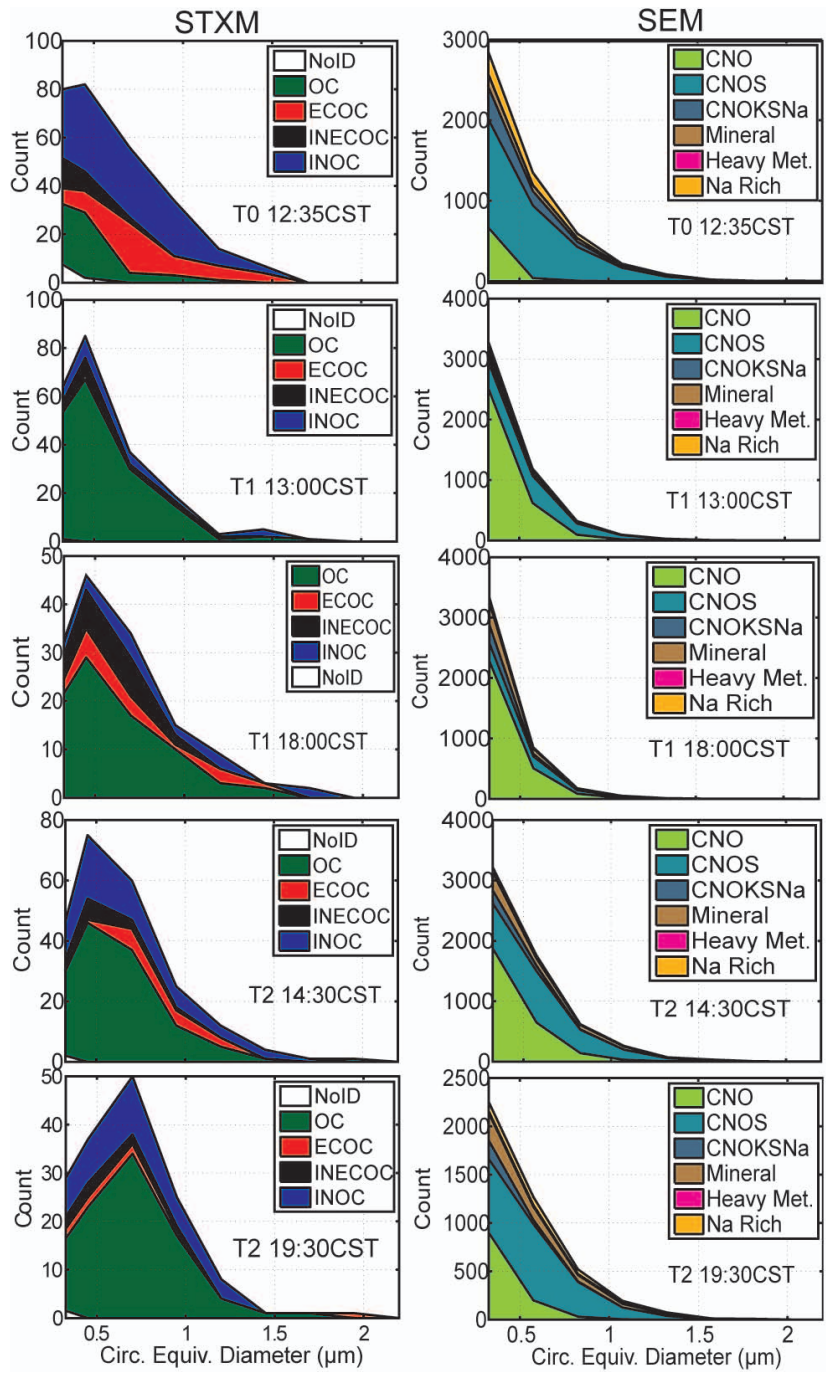

Fig. 10. Chemically resolved size distributions inferred from the STXM/NEXAFS (left) and CCSEM/EDX (right) data sets for the samples collected at three sampling sites during 22 March 2006. Bin widths are all equivalent.

observations are consistent with the increase in homogenous OC particles (from $\mathrm{T} 0$ to $\mathrm{T} 1$ and $\mathrm{T} 2$ ) arising from the growth of particles originating at $\mathrm{T} 0$, but too small to be detected at T0 (using these microscopy methods).

\subsection{Changes in carbon bonding}

To probe photochemical oxidation of $\mathrm{OC}$ in individual particles during transport, averaged NEXAFS spectra from each of the five analyzed samples ( 1 at T0, 2 at T1, and 2 at T2) were deconvoluted using a combination of known electronic transitions. An example is shown in Fig. 11 for the T0 sample. The corresponding fit results for all five samples are given in Table 2. Table 2 lists the energy, electronic transition, and functionality assigned for each peak for all sam-

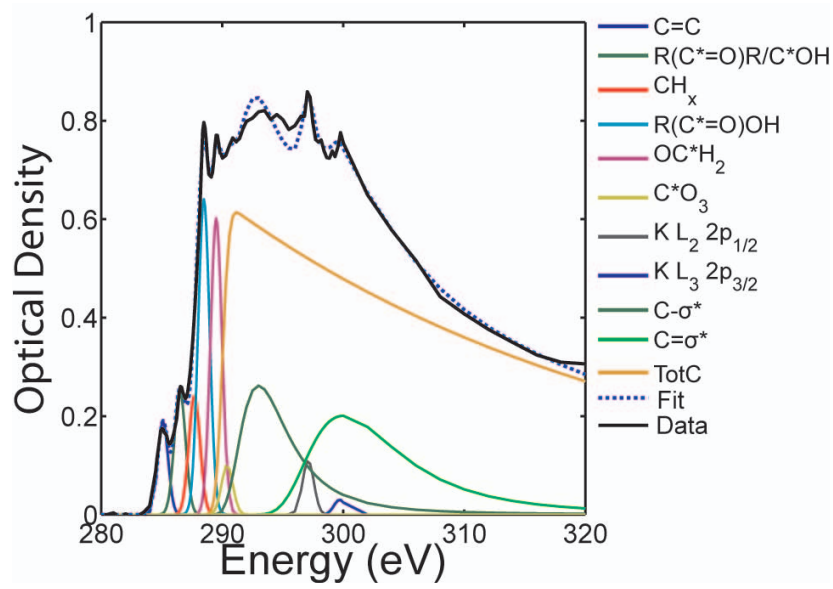

Fig. 11. Spectral deconvolution of the averaged C-edge spectrum of particles detected at the T0 site sample. The solid bold black line is the experimental data, the bold blue line is the best fit using the individual peaks labeled in the legend. A list of peak assignments and relative areas for all sites is given in Table 2 .

ples. The functions used for deconvoluting the NEXAFS peaks for the carbon edge were developed using the methodology described by Stöhr (2003) and Takahamaet al. (2007). In this study, Gaussian peaks were used to fit the $\mathrm{C} 1 \mathrm{~s} \rightarrow \pi^{*}$ and $\mathrm{K} \mathrm{L}_{2}$ and $\mathrm{L}_{3}$ transitions. The broad $\mathrm{C} 1 \mathrm{~s} \rightarrow \sigma^{*}$ transitions were fit with asymmetric Gaussian peaks and the ionization edge step was modeled with a decaying arctangent function. The locations of all peaks were fixed to the positions in Table 2. For fitting the discrete transitions, both regular (FWHM $1 \mathrm{eV}$ ) and asymmetric Gaussian functions were used as described in Sect. 7.2.1 by Stöhr et al. (2003). As shown in Fig. 11, these functions describe the different spectral features of the carbon edge and allow for additional physical insight to be gained from the NEXAFS spectra.

Figure 12 shows peak area trends derived from the deconvolution analysis. Immediately apparent is that the average carbon mass per particle is higher at $\mathrm{T} 1$ and $\mathrm{T} 2$ than at $\mathrm{T} 0$. From Fig. 12e and Table 2, the total carbon mass per particle increased by at least $40 \%$ from T0 to T2. This is accompanied by increases in organic peaks for carboxylic acids, hydrocarbons, and $\mathrm{O}-\mathrm{CH}_{2}$ groups (panels b-d). Hydrocarbonoxygen single bonds may be due to ethers, peroxides, alcohols, organo-nitrates, and organo-sulfates. Carboxylic acids are frequently associated with photochemically produced organic aerosol. These results are consistent with the increase in OC type particles discussed above and would be expected from secondary organic aerosol formation (Seinfeld and Pandis, 1998).

Table 2 also shows that the relative contribution of the peak at $285 \mathrm{eV}$ decreases from T0 to T2. The intensity of this peak is indicative of the number of carbon-carbon double bonds. Using this peak, the percent of $\mathrm{sp}^{2}$ hybridization (\% $\mathrm{sp}^{2}$ ) was calculated using the method described by Hopkins 
Table 2. Peak areas (ODeV/particle) given by deconvolution of the average single particle carbon K-edge spectrum (with EC inclusions removed) for each sampling site and time. See Fig. 9 for an example deconvolution fit to the carbon K-edge. All times given are in CST. Uncertainty in the last digit is reported at the $95 \%$ confidence level and is shown in parentheses.

\begin{tabular}{|c|c|c|c|c|c|c|c|c|}
\hline Energy $(\mathrm{eV})$ & Transition & Functionality & T0 12:35 CST & T1 13:00 CST & T1 18:00 CST & T2 14:30 CST & T2 19:30 CST & Reference \\
\hline 285.1 & $1 \mathrm{~s} \rightarrow \pi^{*}$ & $\mathrm{C}^{*}=\mathrm{C}$ & $0.21( \pm 3)$ & $0.20( \pm 3)$ & $0.18( \pm 2)$ & $0.18( \pm 2)$ & $0.14( \pm 3)$ & $a, b, g$ \\
\hline 286.5 & $\mathrm{~K} 1 \mathrm{~s} \rightarrow \pi^{*}$ or $\mathrm{K} 1 \mathrm{~s} \rightarrow \pi^{*}$ & $\mathrm{R}\left(\mathrm{C}^{*}=\mathrm{O}\right) \mathrm{R}$ or $\mathrm{C}^{*} \mathrm{OH}$ & $0.29( \pm 3)$ & $0.21( \pm 3)$ & $0.21( \pm 2)$ & $0.20( \pm 2)$ & $0.15( \pm 3)$ & $\mathrm{a}, \mathrm{c}$ \\
\hline 287.7 & $\mathrm{~K} 1 \mathrm{~s} \rightarrow \mathrm{C}-\mathrm{H}^{*}$ & $\mathrm{C}^{*} \mathrm{H}, \mathrm{C}^{*} \mathrm{H}_{2}, \mathrm{C}^{*} \mathrm{H}_{3}$ & $0.28( \pm 3)$ & $0.57( \pm 4)$ & $0.47( \pm 3)$ & $0.50( \pm 3)$ & $0.37( \pm 3)$ & $\mathrm{a}, \mathrm{c}$ \\
\hline 288.5 & $\mathrm{~K} 1 \mathrm{~s} \rightarrow \pi^{*}$ & $\mathrm{R}\left(\mathrm{C}^{*}=\mathrm{O}\right) \mathrm{OH}$ & $0.77( \pm 3)$ & $0.88( \pm 3)$ & $0.80( \pm 3)$ & $0.88( \pm 3)$ & $0.73( \pm 3)$ & $\mathrm{a}, \mathrm{c}, \mathrm{d}, \mathrm{g}$ \\
\hline 289.5 & $\mathrm{~K} 1 \mathrm{~s} \rightarrow 3 \mathrm{p} \sigma^{*}$ & $\mathrm{OC}^{*} \mathrm{H}_{2}$ & $0.71( \pm 3)$ & $0.95( \pm 3)$ & $0.78( \pm 3)$ & $0.91( \pm 2)$ & $0.77( \pm 3)$ & $\mathrm{a}, \mathrm{d}$ \\
\hline 290.4 & $\mathrm{~K} 1 \mathrm{~s} \rightarrow \pi^{*}$ & $\mathrm{C}^{*} \mathrm{O}_{3}$ & $0.10( \pm 5)$ & $0.06( \pm 6)$ & $0.11( \pm 6)$ & $0.10( \pm 5)$ & $0.13( \pm 5)$ & $\mathrm{a}, \mathrm{e}$ \\
\hline 297.1, 299.7 & $\mathrm{~L}_{2} 2 \mathrm{p}_{1 / 2} \rightarrow \mathrm{L}_{3} 2 \mathrm{p}_{3 / 2} \rightarrow$ & Potassium $\mathrm{K}^{*}$ & $0.188( \pm 4)$ & $0.046( \pm 2)$ & $0.050( \pm 2)$ & $0.055( \pm 2)$ & $0.142( \pm 3)$ & $\mathrm{c}, \mathrm{f}$ \\
\hline 292.2 & $\mathrm{~K} 1 \mathrm{~s} \rightarrow \sigma^{*}$ & $\mathrm{C}^{*-\mathrm{C}}, \mathrm{C}^{*}-\mathrm{O}$ & $1.5( \pm 3)$ & $1.1( \pm 3)$ & $0.7( \pm 3)$ & $1.1( \pm 2)$ & $0.9( \pm 3)$ & $\mathrm{a}, \mathrm{g}$ \\
\hline 300 & $1 \mathrm{~s} \rightarrow \sigma^{*}$ & $\mathrm{C}^{*}=\mathrm{C}, \mathrm{C}^{*}=\mathrm{O}$ & $2.1( \pm 2)$ & $1.2( \pm 3)$ & $1.4( \pm 3)$ & $1.3( \pm 2)$ & $1.5( \pm 3)$ & $\mathrm{a}$ \\
\hline 294.5 & Edge Step & Total Carbon & $12.7( \pm 5)$ & $18.3( \pm 6)$ & $16.9( \pm 6)$ & $16.7( \pm 4)$ & $14.9( \pm 6)$ & $\mathrm{a}$ \\
\hline
\end{tabular}

a (Stöhr, 2003)

b (Hopkins et al., 2007b)

c (Takahama et al., 2007)

d (Tivanski et al., 2007)

e (Benzerara et al., 2005)

f (Yoon et al., 2006)

g (Hitchcock et al., 1992)

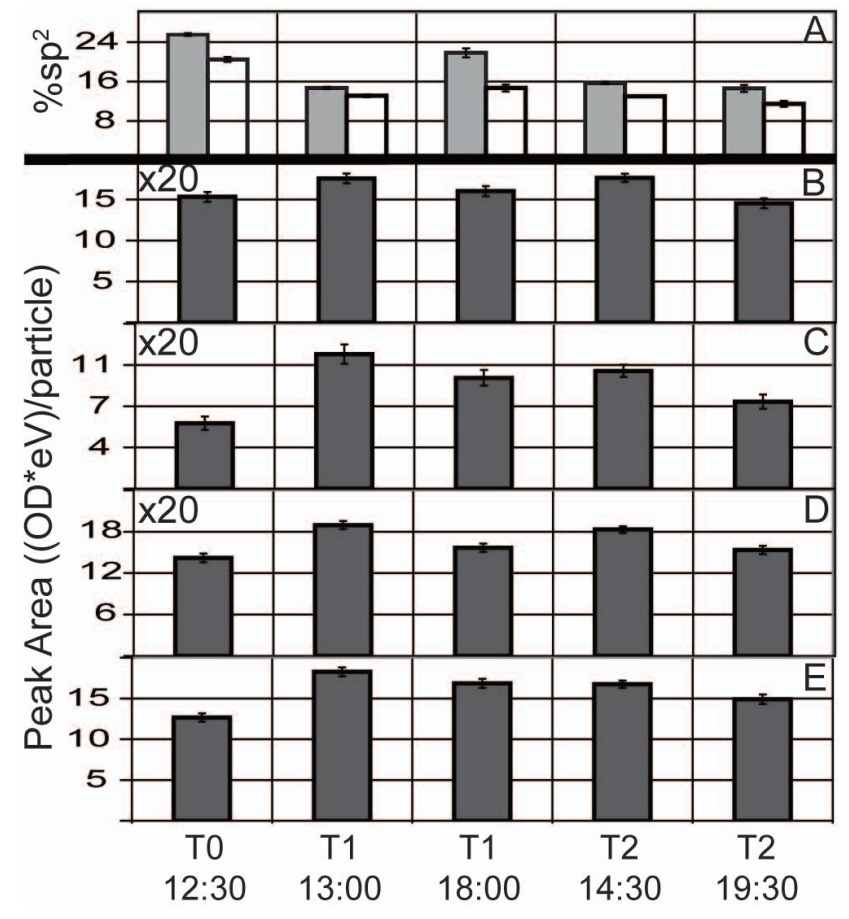

Fig. 12. Trends of (A) \%sp2 bonds for whole particles (gray bars) and for organic coatings (white bars), (B) $\mathrm{COOH}$ groups, (C) $\mathrm{CHx}$ groups, (D) $\mathrm{OCH}_{2}$ groups and (E) total carbon. Error bars represent 95\% confidence interval.

et al. (2007b). The obtained results are plotted in Fig. 12 (panel a). The decrease in $\mathrm{sp}^{2}$ bonds detected in particles from $\mathrm{T} 0$ to $\mathrm{T} 1$ and $\mathrm{T} 2$ samples could be due to any of the following reasons: a lower number fraction of EC particles, an increase in organic mass, or the destruction of $\mathrm{sp}^{2}$ bonds due to atmospheric oxidation. To explore this further, particles containing only OC were examined and the combined $\% \mathrm{sp}^{2}$ was calculated for each sample (Fig. 12, panel a). The OC at $\mathrm{T} 0$ contained the largest amount of $\mathrm{sp}^{2}$ hybridized bonds and the decreasing trend is equally apparent when EC particles were included. It follows that decrease in $\mathrm{sp}^{2}$ bonds is likely due to OC oxidation. However, the condensation of organic matter onto particles may also play an additional role in the decreasing relative contribution of the $\mathrm{sp}^{2}$ carbon within individual particles. Based on our results, these two processes cannot be decoupled.

Although this paper focuses on 22 March as a case study, a similar analysis was performed on a limited number of particles for 20 March - a day also expected to have the T0 to T2 transport pattern (Doran et al., 2007). Primary differences between 20 and 22 March are the absence of the homogenous OC phase at the rural locations and lower sulfur concentrations. The rate of organic condensation could have been much faster on 22 March compared to 20 March, allowing the OC particles to become large enough to be detected by our microscopic methods. Another difference observed between 20 and 22 March, was a higher relative fraction of EC observed at T1 and T2 on 20 March. However, all of the trends in organic functionality between 20 and 22 March were similar, suggesting an increase in organic mass with time and distance from the center of the city.

\section{Conclusions}

In this study, the evolution of individual organic carbon particles was investigated as a function of time and distance during transport away from Mexico City. An increase in organic functionality and total carbon mass (of at least $40 \%$ 
per particle) during the transport event of 22 March 2006 was observed. The mixing state of the particles evolved as they advected further away from the city. A homogenous OC particle type, a minor contributor at $\mathrm{T} 0$, is the dominant type at the T1 (suburban) and T2 (rural) sites. These homogenous OC particles were likely formed from condensational growth of smaller particles.

These results are consistent with several other results from the MILAGRO campaign. The increase in the fraction of purely organic particles together with the decrease in the fraction of elemental carbon particle types is consistent with the increase in the OC to EC ratio measured by Doran et al. (2007) and the increase in OC with plume age measured by Kleinman (Doran et al., 2007; Kleinman et al., 2008). Since organics are strongly scattering and weakly absorbing, their increase is also consistent with the increase in single scattering albedo (ratio of scattering to absorption) later in the day (Marley et al., 2009a). Also, several researchers detected high levoglucosan concentrations, a biomass burning marker, on this sampling day (Aiken et al., 2009; Stone et al., 2008). Similarly, we observed elevated levels of $\mathrm{O}-\mathrm{CH}_{2}$ groups, a potential component of sugar molecules, such as levoglucosan. Higher levels of $\mathrm{O}-\mathrm{CH}_{2}$ functional groups at $\mathrm{T} 1$ for 22 March, could indicate larger biomass burning contributions at this site.

At the city center, we observed that particles have large inorganic inclusions composed of sulfur, oxygen, potassium and nitrogen surrounded by an organic coating. The coating contained both sulfur and nitrogen, suggesting that organic nitrogen and/or sulfur containing compounds are present, or alternatively, that inorganic compounds are homogenously mixed within the particle $\mathrm{OC}$ phase. The observation of a phase with both organic and inorganic species is important because the particle composition largely controls microphysical properties such as hygroscopicity, heterogeneous reactivity, vapor pressure and optical properties (Cappa et al., 2008; Rood et al., 1989). These results should be compared to models to evaluate our understanding of organic aerosol aging mechanisms in a polluted urban atmosphere.

Acknowledgements. The authors gratefully acknowledge financial support provided by the Atmospheric Science Program of the Department of Energy's office of Biological and Environmental Research. R. C. Moffet acknowledges additional financial support from the Lawrence Berkeley National Laboratory Glenn T. Seaborg Fellowship. R. C. Moffet also thanks Satoshi Takahama for extremely helpful guidance with STXM data analysis techniques. The STXM/NEXAFS particle analysis was performed at beamlines 11.0.2 and 5.3.2 and the SXRF analysis at beamline 10.3.1 at the Advanced Light Source at Lawrence Berkeley National Laboratory. The work at the Advanced Light Source was supported by the Director, Office of Science, Office of Basic Energy Sciences, of the US Department of Energy under Contract No. DE-AC02-05CH11231. The CCSEM/EDX particle analysis was performed in the Environmental Molecular Sciences Laboratory, a national scientific user facility sponsored by the Department of Energy's Office of Biological and Environmental Research at
Pacific Northwest National Laboratory. PNNL is operated by the US Department of Energy by Battelle Memorial Institute under contract DE-AC06-76RL0. T. R. Henn thanks the student exchange program between the University of Würzburg and U. C. Berkeley (curator Professor A. Forchel, Würzburg and NSF IGERT program at UCB, DGE-0333455, Nanoscale Science and Engineering-From Building Blocks to Functional Systems). S. S. Cliff and K. D. Perry gratefully acknowledge Yongjing Zhao and Donna Hamamoto for analytical support at beamline 10.3.1.

Edited by: J. Gaffney

\section{References}

Adachi, K., and Buseck, P. R.: Internally mixed soot, sulfates, and organic matter in aerosol particles from Mexico City, Atmos. Chem. Phys., 8, 6469-6481, 2008, http://www.atmos-chem-phys.net/8/6469/2008/.

Aiken, A. C., Salcedo, D., Cubison, M. J., Huffman, J. A., DeCarlo, P. F., Ulbrich, I. M., Docherty, K. S., Sueper, D., Kimmel, J. R., Worsnop, D. R., Trimborn, A., Northway, M., Stone, E. A., Schauer, J. J., Volkamer, R., Fortner, E., Foy, B. d., Wang, J., Laskin, A., Shutthanandan, V., Zheng, J., Zhang, R., Gaffney, J., Marley, N. A., Paredes-Miranda, G., Arnott, W. P., Molina, L. T., Sosa, G., and Jimenez, J. L.: Mexico City aerosol analysis during MILAGRO using high resolution aerosol mass spectrometry at the urban supersite (T0) - Part 1: Fine particle composition and organic source apportionment, Atmos. Chem. Phys., 9, 66336653, 2009, http://www.atmos-chem-phys.net/9/6633/2009/.

Alexander, D. T. L., Crozier, P. A., and Anderson, J. R.: Brown carbon spheres in East Asian outflow and their optical properties, Science, 321, 833-836, 2008.

Bae, M. S., Hong, C. S., Kim, Y. J., Han, J. S., Moon, K. J., Kondo, Y., Komazaki, Y., and Miyazaki, Y.: Intercomparison of two different thermal-optical elemental carbons and optical black carbon during ABC-EAREX2005, Atmos. Environ., 41, 2791-2803, 2007.

Beetz, T., Feser, M., Fleckenstein, H., Benjamin Hornberger, Jacobsen, C., Kirz, J., Lerotic, M., Lima, E., Lu, M., Sayre, D., Shapiro, D., Stein, A., Tennant, D., and Wirick, S.: Soft X-ray microscopy at the NSLS, Synch. Rad. News, 16, 11-15, 2003.

Bench, G., Grant, P. G., Ueda, D., Cliff, S. S., Perry, K. D., and Cahill, T. A.: The use of STIM and PESA to measure profiles of aerosol mass and hydrogen content, respectively, across mylar rotating drums impactor samples, Aerosol Sci. Technol., 36, 642-651, 2002.

Benzerara, K., Yoon, T. H., Menguy, N., Tyliszczak, T., and Brown, G. E.: Nanoscale environments associated with bioweathering of a Mg-Fe-pyroxene, Proc. Natl. Acad. Sci. USA, 102, 979-982, 2005.

Braun, A., Kubatova, A., Wirick, S., and Mun, S. B.: Radiation damage from EELS and NEXAFS in diesel soot and diesel soot extracts, J. Electron Spectrosc. Relat. Phenom., 170, 42-48, 2009.

Cahill, T. A. and Wayakabashi, P.: Compositional analysis of size segregated aerosol samples, ACS Adv. Chem. Ser., 232, 211228, 1993.

Canagaratna, M. R., Jayne, J. T., Jimenez, J. L., Allan, J. D., Alfarra, M. R., Zhang, Q., Onasch, T. B., Drewnick, F., Coe, H., 
Middlebrook, A., Delia, A., Williams, L. R., Trimborn, A. M., Northway, M. J., DeCarlo, P. F., Kolb, C. E., Davidovits, P., and Worsnop, D. R.: Chemical and microphysical characterization of ambient aerosols with the aerodyne aerosol mass spectrometer, Mass Spectrom. Rev., 26, 185-222, 2007.

Cappa, C. D., Lovejoy, E. R., and Ravishankara, A. R.: Evidence for liquid-like and nonideal behavior of a mixture of organic aerosol components, Proc. Natl. Acad. Sci. USA, 105, 18687-18691, 2008.

de Foy, B., Fast, J. D., Parch, S. J., Phillips, D., Walters, J. T., Coulter, R. L., Martin, T. J., Pekour, M. S., Shaw, W. J., Kastendeuch, P. P., Marley, N. A., Retama, A., and Molina, L. T.: Basin-Scale Wind Transport During the MILAGRO Field Campaign and Comparison to Climatology Using Cluster Analysis, Atmos. Chem. Phys., 8, 1209-1224, 2008,

http://www.atmos-chem-phys.net/8/1209/2008/.

Doran, J. C., Abbott, S., Archuleta, J., Bian, X., Chow, J., Coulter, R. L., de Wekker, S. F. J., Edgerton, S., Elliott, S., Fernandez, A., Fast, J. D., Hubbe, J. M., King, C., Langley, D., Leach, J., Lee, J. T., Martin, T. J., Martinez, D., Martinez, J. L., Mercado, G., Mora, V., Mulhearn, M., Pena, J. L., Petty, R., Porch, W., Russell, C., Salas, R., Shannon, J. D., Shaw, W. J., Sosa, G., Tellier, L., Templeman, B., Watson, J. G., White, R., Whiteman, C. D., and Wolfe, D.: The IMADA-AVER boundary layer experiment in the Mexico City area, B. Am. Meteorol. Soc., 79, 2497-2508, 1998.

Doran, J. C., Barnard, J. C., Arnott, W. P., Cary, R., Coulter, R., Fast, J. D., Kassianov, E. I., Kleinman, L., Laulainen, N. S., Martin, T., Paredes-Miranda, G., Pekour, M. S., Shaw, W. J., Smith, D. F., Springston, S. R., and Yu, X. Y.: The T1-T2 study: evolution of aerosol properties downwind of Mexico City, Atmos. Chem. Phys., 7, 1585-1598, 2007, http://www.atmos-chem-phys.net/7/1585/2007/.

Doran, J. C., Fast, J. D., Barnard, J. C., Laskin, A., Desyaterik, Y., and Gilles, M. K.: Applications of lagrangian dispersion modeling to the analysis of changes in the specific absorption of elemental carbon, Atmos. Chem. Phys., 8, 1377-1389, 2008, http://www.atmos-chem-phys.net/8/1377/2008/.

Egerton, R. F., Li, P., and Malac, M.: Radiation damage in the TEM and SEM, Micron, 35, 399-409, 2004.

Fast, J. D. and Easter, R. C.: Lagrangian particle dispersion model compatible with WRF, 7th WRF Users Workshop, p. 6.2, 2006.

Fast, J. D., Aiken, A., L.Alexander, Campos, T., Canagaratna, M., Chapman, E., DeCarlo, P., Foy, B. d., Gaffney, J., Gouw, J. d., Doran, J. C., Emmons, L., Hodzic, A., Herndon, S., Huey, G., Jayne, J., Jimene, J., Kleinman, L., Kuster, W., Marley, N., Ochoa, C., Onasch, T., Pekour, M., Song, C., Warneke, C., Welsh-Bon, D., Wiedinmyer, C., Yu, X.-Y., and Zaveri, R.: Evaluating simulated primary anthropogenic and biomass burning organic aerosols during MILAGRO: Implications for assessing treatments of secondary organic aerosols, Atmos. Chem. Phys., 9, 6191-6215, 2009,

http://www.atmos-chem-phys.net/9/6191/2009/.

Fuzzi, S., Andreae, M. O., Huebert, B. J., Kulmala, M., Bond, T. C., Boy, M., Doherty, S. J., Guenther, A., Kanakidou, M., Kawamura, K., Kerminen, V. M., Lohmann, U., Russell, L. M., and Pöschl, U.: Critical assessment of the current state of scientific knowledge, terminology, and research needs concerning the role of organic aerosols in the atmosphere, climate, and global change, Atmos. Chem. Phys., 6, 2017-2038, 2006, http://www.atmos-chem-phys.net/6/2017/2006/.

Geron, C.: Carbonaceous aerosol over a Pinus taeda forest in Central North Carolina, USA, Atmos. Environ., 43, 959-969, 2009.

Hitchcock, A. P., Urquhart, S. G., and Rightor, E. G.: Inner-Shell Spectroscopy of Benzaldehyde, Terephthalaldehyde, Ethyl Benzoate, Terephthaloyl Chloride, and Phosgene - Models for Core Excitation of Poly(Ethylene-Terephthalate), J. Phys. Chem., 96, 8736-8750, 1992.

Hopkins, R. J., Lewis, K., Desyaterik, Y., Wang, Z., Tivanski, A. V., Arnott, W. P., Laskin, A., and Gilles, M. K.: Correlations between optical, chemical and physical properties of biomass burn aerosols, Geophys. Res. Lett., 34, L18806, doi:10.1029/2007GL030502, 2007a.

Hopkins, R. J., Tivanski, A. V., Marten, B. D., and Gilles, M. K.: Chemical Bonding and Structure of Black Carbon Reference Materials and Individual Carbonaceous Atmospheric Aerosols, J. Aerosol Sci., 38, 573-591, 2007b.

Hopkins, R. J., Desyaterik, Y., Tivanski, A. V., Zaveri, R. A., Berkowitz, C. M., Tyliszczak, T., Gilles, M. K., and Laskin, A.: Chemical speciation of sulfur in marine cloud droplets and particles: Analysis of individual particles from the marine boundary layer over the California current, J. Geophys. Res.-Atmos., 113, D04209, doi:10.1029/2007JD008954, 2008.

Iida, K., Stolzenburg, M. R., McMurry, P. H., and Smith, J. N.: Estimating nanoparticle growth rates from size-dependent charged fractions: Analysis of new particle formation events in Mexico City, J. Geophys. Res.-Atmos., 113, D05207, doi:10.1029/2007JD009260, 2008.

Johnson, K. S., de Foy, B., Zuberi, B., Molina, L. T., Molina, M. J., Xie, Y., Laskin, A., and Shutthanandan, V.: Aerosol composition and source apportionment in the Mexico City Metropolitan Area with PIXE/PESA/STIM and multivariate analysis, Atmos. Chem. Phys., 6, 4591-4600, 2006,

http://www.atmos-chem-phys.net/6/4591/2006/.

Katrinak, K. A., Rez, P., and Buseck, P. R.: Structural Variations in Individual Carbonaceous Particles from an Urban Aerosol, Environ. Sci. Technol., 26, 1967-1976, 1992.

Kilcoyne, A. L. D., Tyliszczak, T., Steele, W. F., Fakra, S., Hitchcock, P., Franck, K., Anderson, E., Harteneck, B., Rightor, E. G., Mitchell, G. E., Hitchcock, A. P., Yang, L., Warwick, T., and Ade, H.: Interferometer-controlled scanning transmission X-ray microscopes at the Advanced Light Source, J. Synchrotron Radiat., 10, 125-136, 2003.

Kirz, J. and Rarback, H.: Soft-X-Ray Microscopes, Rev. Sci. Instrum., 56, 1-13, 1985.

Kleinman, L. I., Springston, S. R., Daum, P. H., Lee, Y. N., Nunnermacker, L. J., Senum, G. I., Wang, J., Weinstein-Lloyd, J., Alexander, M. L., Hubbe, J., Ortega, J., Canagaratna, M. R., and Jayne, J.: The time evolution of aerosol composition over the Mexico City plateau, Atmos. Chem. Phys., 8, 1559-1575, 2008, http://www.atmos-chem-phys.net/8/1559/2008/.

Kleinman, L. I., Springston, S. R., Wang, J., Daum, P. H., Lee, Y. N., Nunnermacker, L. J., Senum, G. I., Weinstein-Lloyd, J., Alexander, M. L., Hubbe, J., Ortega, J., Zaveri, R. A., Canagaratna, M. R., and Jayne, J.: The time evolution of aerosol size distribution over the Mexico City plateau, Atmos. Chem. Phys., 9, 4261-4278, 2009,

http://www.atmos-chem-phys.net/9/4261/2009/.

Laskin, A., Iedema, M. J., and Cowin, J. P.: Time-resolved aerosol 
collector for CCSEM/EDX single-particle analysis, Aerosol Sci. Technol., 37, 246-260, 2003.

Laskin, A., Cowin, J. P., and Iedema, M. J.: Analysis of individual environmental particles using modern methods of electron microscopy and X-ray microanalysis, J. Electron Spectrosc. Relat. Phenom., 150, 260-274, 2006.

Lessard, R., Cuny, J., Cooper, G., and Hitchcock, A. P.: Inner-shell excitation of gas phase carbonates and -dicarbonyl compounds, Chem. Phys., 331, 289-303, 2007.

Li, J., Posfai, M., Hobbs, P. V., and Buseck, P. R.: Individual aerosol particles from biomass burning in southern Africa: 2, Compositions and aging of inorganic particles, J. Geophys. Res.-Atmos., 108, 8484, doi:10.1029/2002JD002310, 2003.

Maria, S. F., Russell, L. M., Gilles, M. K., and Myneni, S. C. B.: Organic aerosol growth mechanisms and their climate-forcing implications, Science, 306, 1921-1924, 2004.

Marley, N. A., Gaffney, J. S., Castro, T., Salcido, A., and Frederick, J.: Measurements of aerosol absorption and scattering in the Mexico City Metropolitan Area during the MILAGRO field campaign: a comparison of results from the T0 and T1 sites, Atmos. Chem. Phys., 9, 189-206, 2009a,

http://www.atmos-chem-phys.net/9/189/2009/.

Marley, N. A., Gaffney, J. S., Tackett, M., Sturchio, N. C., Heraty, L., Martinez, N., Hardy, K. D., Marchany-Rivera, A., Guilderson, T., MacMillan, A., and Steelman, K.: The impact of biogenic carbon sources on aerosol absorption in Mexico City, Atmos. Chem. Phys., 9, 1537-1549, 2009b,

http://www.atmos-chem-phys.net/9/1537/2009/.

Maxwell, J. A., Campbell, J. L., and Teesdale, W. J.: The Guelph Pixe Software Package, Nucl. Instrum. Meth. B, 43, 218-230, 1989.

Moffet, R. C., de Foy, B., Molina, L. T., Molina, M. J., and Prather, K. A.: Measurement of ambient aerosols in northern Mexico City by single particle mass spectrometry, Atmos. Chem. Phys., 8, 4499-4516, 2008a,

http://www.atmos-chem-phys.net/8/4499/2008/.

Moffet, R. C., Desyaterik, Y., Hopkins, R. J., Tivanski, A. V., Gilles, M. K., Wang, Y., Shutthanandan, V., Molina, L. T., Abraham, R. G., Johnson, K. S., Mugica, V., Molina, M. J., Laskin, A., and Prather, K. A.: Characterization of aerosols containing $\mathrm{Zn}, \mathrm{Pb}$, and $\mathrm{Cl}$ from an industrial region of Mexico City, Environ. Sci. Technol., 42, 7091-7097, 2008b.

Moffet, R. C., Qin, X. Y., Rebotier, T., Furutani, H., and Prather, K. A.: Chemically segregated optical and microphysical properties of ambient aerosols measured in a single-particle mass spectrometer, J. Geophys. Res.-Atmos., 113, D12213, doi:10.1029/2007JD009393, 2008c.

Moffet, R. C., Henn, T. R., Kilcoyne, A. L. D., Tyliszczak, T., Laskin, A., and Gilles, M. K.: Automated Analysis of Individual Nanometer Sized Carbonaceous Particles using Soft X-ray Spectromicroscopy, Anal. Chem., in preparation, 2010.

Molina, L. T., Kolb, C. E., de Foy, B., Lamb, B. K., Brune, W. H., Jimenez, J. L., Ramos-Villegas, R., Sarmiento, J., ParmoFigueroa, V. H., Cardenias, B., Gutierrez-Avedoy, V., and Molina, M. J.: Air quality in North America's most populous city - overview of MCMA-2003 Campaign, Atmos. Chem. Phys., 7, 2447-2473, 2007,

http://www.atmos-chem-phys.net/7/2447/2007/.

Molina, M. J. and Molina, L. T. (eds.): Air Quality in the Mexico
Megacity: An Integrated Assessment, Kluwer Academic, The Netherlands, 2002.

Murphy, D. M.: The design of single particle laser mass spectrometers, Mass Spectrom. Rev., 26, 150-165, 2007.

Nienow, A. M. and Roberts, J. T.: Heterogenous chemistry of carbon aerosols Annu. Rev. Phys. Chem., 57, 105-128, 2006.

Posfai, M., Simonics, R., Li, J., Hobbs, P. V., and Buseck, P. R.: Individual aerosol particles from biomass burning in southern Africa: 1. Compositions and size distributions of carbonaceous particles, J. Geophys. Res.-Atmos., 108, 8483, doi:10.1029/2002JD002291, 2003.

Reid, J. S., Koppmann, R., Eck, T. F., and Eleuterio, D. P.: A review of biomass burning emissions part II: intensive physical properties of biomass burning particles, Atmos. Chem. Phys., 5, 799825, 2005, http://www.atmos-chem-phys.net/5/799/2005/.

Ro, C. U., Osan, J., Szaloki, I., de Hoog, J., Worobiec, A., and Van Grieken, R.: A Monte Carlo program for quantitative electroninduced X-ray analysis of individual particles, Anal. Chem., 75, 851-859, 2003.

Ro, C. U., Kim, H., and Van Grieken, R.: An expert system for chemical speciation of individual particles using low-Z particle electron probe X-ray microanalysis data, Anal. Chem., 76, 13221327, 2004.

Robinson, A. L., Donahue, N. M., Shrivastava, M. K., Weitkamp, E. A., Sage, A. M., Grieshop, A. P., Lane, T. E., Pierce, J. R., and Pandis, S. N.: Rethinking organic aerosols: Semivolatile emissions and photochemical aging, Science, 315, 1259-1262, 2007.

Rood, M. J., Shaw, M. A., Larson, T. V., and Covert, D. S.: Ubiquitous Nature of Ambient Metastable Aerosol, Nature, 337, 537539, 1989.

Russell, L. M., Maria, S. F., and Myneni, S. C. B.: Mapping organic coatings on atmospheric particles, Geophys. Res. Lett., 29, 1779, doi:10.1029/2002GL014874, 2002.

Salcedo, D., Onasch, T. B., Dzepina, K., Canagaratna, M. R., Zhang, Q., Huffman, J. A., DeCarlo, P. F., Jayne, J. T., Mortimer, P., Worsnop, D. R., Kolb, C. E., Johnson, K. S., Zuberi, B., Marr, L. C., Volkamer, R., Molina, L. T., Molina, M. J., Cardenas, B., Bernabe, R. M., Marquez, C., Gaffney, J. S., Marley, N. A., Laskin, A., Shutthanandan, V., Xie, Y., Brune, W., Lesher, R., Shirley, T., and Jimenez, J. L.: Characterization of ambient aerosols in Mexico City during the MCMA-2003 campaign with Aerosol Mass Spectrometry: results from the CENICA Supersite, Atmos. Chem. Phys., 6, 925-946, 2006, http://www.atmos-chem-phys.net/6/925/2006/.

Sayre, D., Kirz, J., Feder, R., Kim, D. M., and Spiller, E.: Transmission Microscopy of Unmodified Biological-Materials - Comparative Radiation Dosages with Electrons and Ultrasoft X-Ray Photons, Ultramicroscopy, 2, 337-349, 1977.

Seinfeld, J. H. and Pandis, S. N.: Atmospheric Chemistry and Physics, 1st ed., John Wiley \& Sons, Inc., New York, USA, 1998.

Seinfeld, J. H. and Pankow, J. F.: Organic atmospheric particulate material, Annu. Rev. Phys. Chem., 54, 121-140, doi:10.1146/annurev.physchem.1154.011002.103756, 2003.

Shaw, W. J., Pekour, M. S., Coulter, R. L., Martin, T. J., and Walters, J. T.: The daytime mixing layer observed by radiosonde, profiler, and LIDAR during MILAGRO, Atmos. Chem. Phys. Discuss., 7, 15025-15065, 2007,

http://www.atmos-chem-phys-discuss.net/7/15025/2007/.

Shutthanandan, V., Thevuthasan, S., Disselkamp, R., Stroud, A., 
Cavanagh, A., Adams, E. M., Baer, D. R., Barrie, L. A., Cliff, S. S., Jimenez-Cruz, M., and Cahill, T. A.: Development of PIXE, PESA and transmission ion microscopy capability to measure aerosols by size and time, Nucl. Instrum. Meth. B, 189, 284-288, 2002.

Smith, J. N., Dunn, M. J., VanReken, T. M., Iida, K., Stolzenburg, M. R., McMurry, P. H., and Huey, L. G.: Chemical composition of atmospheric nanoparticles formed from nucleation in Tecamac, Mexico: Evidence for an important role for organic species in nanoparticle growth, Geophys. Res. Lett., 35, L04808, doi:10.1029/2007GL032523, 2008.

Stöhr, J.: NEXAFS Spectroscopy, 1st ed., Springer-Verlag, Berlin, Heidelberg, Germany, 2003.

Stone, E. A., Snyder, D. C., Sheesley, R. J., Sullivan, A. P., Weber, R. J., and Schauer, J. J.: Source apportionment of fine organic aerosol in Mexico City during the MILAGRO experiment 2006, Atmos. Chem. Phys., 8, 1249-1259, 2008, http://www.atmos-chem-phys.net/8/1249/2008/.

Takahama, S., Gilardoni, S., Russell, L. M., and Kilcoyne, A. L. D.: Classification of multiple types of organic carbon composition in atmospheric particles by scanning transmission X-ray microscopy analysis, Atmos. Environ., 41, 9435-9451, 2007.

Takahama, S., Gilardoni, S., and Russell, L. M.: Singleparticle oxidation state and morphology of atmospheric iron aerosols, J. Geophys. Res.-Atmos., 113, D22202, doi:10.1029/2008JD009810, 2008.

Tivanski, A. V., Hopkins, R. J., Tyliszcazak, T., and Gilles, M. K.: Oxygenated Interface on Biomass Burn Tar Balls Determined by Single Particle Scanning Transmission X-ray Microscopy, J. Phys. Chem. A, 111, 5448-5458, 2007.

Urquhart, S. G. and Ade, H.: Trends in the Carbonyl Core (C 1S, O 1S) $->$ pi $^{*} \mathrm{C}=\mathrm{O}$ Transition in the Near-Edge X-ray Absorption Fine Structure Spectra of Organic Molecules, J. Phys. Chem. B, 106, 8531-8538, 2002. van Poppel, L. H., Friedrich, H., Spinsby, J., Chung, S. H., Seinfeld, J. H., and Buseck, P. R.: Electron tomography of nanoparticle clusters: Implications for atmospheric lifetimes and radiative forcing of soot, Geophys. Res. Lett., 32, L24811, doi:10.1029/2005GL024461, 2005.

Volkamer, R., Jimenez, J. L., San Martini, F., Dzepina, K., Zhang, Q., Salcedo, D., Molina, L. T., Worsnop, D. R., and Molina, M. J.: Secondary organic aerosol formation from anthropogenic air pollution: Rapid and higher than expected, Geophys. Res. Lett., 33, L17811, doi:10.1029/2006GL026899, 2006.

Yokelson, R. J., Urbanski, S. P., Atlas, E. L., Toohey, D. W., Alvarado, E. C., Crounse, J. D., Wennberg, P. O., Fisher, M. E., Wold, C. E., Campos, T. L., Adachi, K., Buseck, P. R., and Hao, W. M.: Emissions from forest fires near Mexico City, Atmos. Chem. Phys., 7, 5569-5584, 2007, http://www.atmos-chem-phys.net/7/5569/2007/.

Yoon, T. H., Benzerara, K., Ahn, S., Luthy, R. G., Tyliszczak, T., and Brown, G. E.: Nanometer-scale chemical heterogeneities of black carbon materials and their impacts on PCB sorption properties: Soft X-ray spectromicroscopy study, Environ. Sci. Technol., 40, 5923-5929, 2006.

Zhang, Q., Jimenez, J. L., Canagaratna, M. R., Allan, J. D., Coe, H., Ulbrich, I., Alfarra, M. R., Takami, A., Middlebrook, A. M., Sun, Y. L., Dzepina, K., Dunlea, E., Docherty, K., DeCarlo, P. F., Salcedo, D., Onasch, T., Jayne, J. T., Miyoshi, T., Shimono, A., Hatakeyama, S., Takegawa, N., Kondo, Y., Schneider, J., Drewnick, F., Borrmann, S., Weimer, S., Demerjian, K., Williams, P., Bower, K., Bahreini, R., Cottrell, L., Griffin, R. J., Rautiainen, J., Sun, J. Y., Zhang, Y. M., and Worsnop, D. R.: Ubiquity and dominance of oxygenated species in organic aerosols in anthropogenically-influenced Northern Hemisphere midlatitudes, Geophys. Res. Lett., 34, L13801, doi:10.1029/2007GL029979, 2007. 